\title{
Temperature Rise and Thermal Deformation of Magnetic Pole of MLDSB under Multiple Physical Field Coupling
}

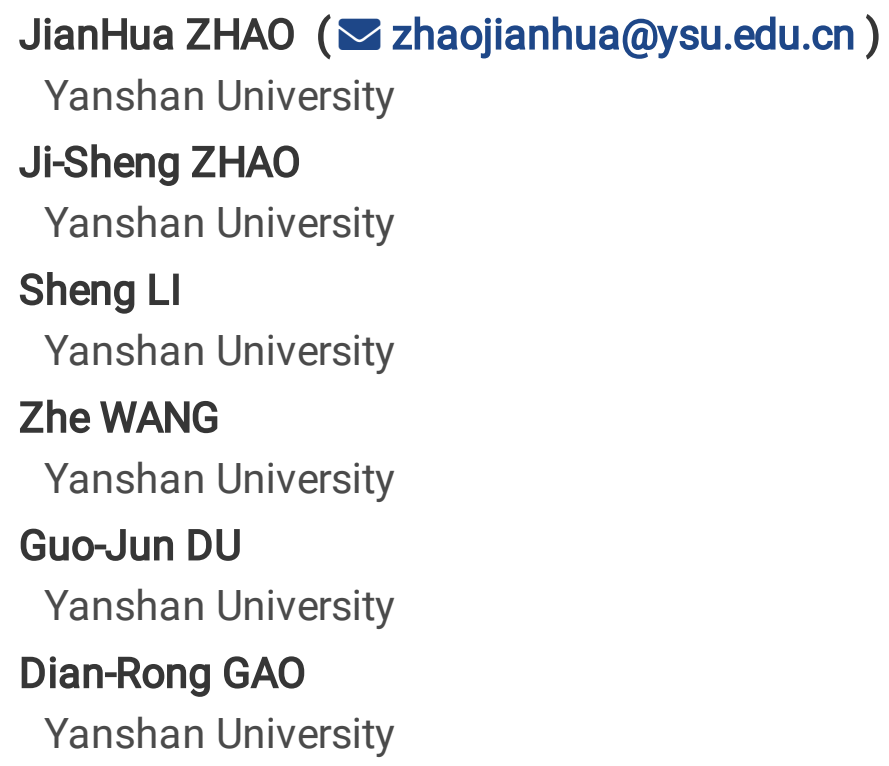

\section{Original Article}

Keywords: Magnetic-Liquid Double Suspension Bearing, Multiple physical field coupling, Temperature rise, Thermal deformation, Inlet pressure, Current

Posted Date: May 14th, 2020

DOI: https://doi.org/10.21203/rs.3.rs-28168/v1

License: (9) This work is licensed under a Creative Commons Attribution 4.0 International License. Read Full License 


\section{Title page}

\section{Temperature Rise and Thermal Deformation of Magnetic Pole of MLDSB under Multiple Physical Field Coupling}

Jian-Hua Zhao, born in 1983, is currently an associate professor at Mechanical Engineering College, Yanshan University, China. He received his bachelor degree in 2003, master degree in 2010, $\mathrm{PhD}$ degree in 2013 from Yanshan University, China. His research interests include simulation and analysis of hydrostatic bearing, Magnetic-Liquid Double Suspension Bearing System.

Tel: +86-15933502864; E-mail: zhaojianhua@ysu.edu.cn

Ji-Sheng ZHAO, born in 1995, is currently a postgraduate student of yanshan university, China.

E-mail: 657183196@qq.com

Sheng LI, born in 1995, is currently a postgraduate student of Yanshan University, China.

E-mail: 13394466235@163.com

Zhe WANG, born in 1994, is currently a postgraduate student of Yanshan University, China.

E-mail: 1114048872@qq.com

Guo-Jun DU, born in 1961, is currently a professor at Yanshan University, China. He received his bachelor degree in 1983 from Northeast Heavy Machinery Institute, China. He received his master degree in 1991, PhD degree in 2004 from Yanshan University, China. His research interests include nonlinear vibration of complicated shell structure.

Tel: +86-18633515962; E-mail: dugj2002@ysu.edu.cn

Dian-Rong GAO, born in 1962, is currently a professor and a PhD candidate supervisor at Mechanical Engineering College, Yanshan University, China. He received his bachelor degree in 1984, master degree in 2010 from Northeast Heavy Machinery Institute, China.He received his $\mathrm{PhD}$ degree in 2001 from Yanshan University, China. His research interests include fluid power transmission and control.

E-mail: gaodr@ysu.edu.cn

\section{Corresponding author: Jian-Hua Zhao E-mail: zhaojianhua@ysu.edu.cn}




\title{
Temperature Rise and Thermal Deformation of Magnetic Pole of MLDSB under Multiple Physical Field Coupling
}

\author{
Jian-Hua ZHAO ${ }^{1,2,3} \cdot$ Ji-Sheng $\mathrm{ZHAO}^{2} \cdot$ Sheng $\mathrm{LI}^{2} \cdot \mathrm{Zhe} \mathrm{WANG}^{2} \cdot$ Guo-Jun DU $^{1} \cdot$ Dian-Rong GAO ${ }^{2}$
}

Received June xx, 201x; revised February xx, 201x; accepted March xx, 201x

(C) Chinese Mechanical Engineering Society and Springer-Verlag Berlin Heidelberg 2017

\begin{abstract}
The thermal deformation of magnetic poles caused by the heat loss of the coils of Magnetic Liquid Double Suspension Bearing (MLDSB) can reduced the gap between magnetic poles and magnetic sleeve, and the probability and degree of impact-rub can be increased in the working process of MLDSB. And the coatings of magnetic poles and magnetic sleeve can be worn overly, and the operation stability and service life of MLDSB will be reduced severely. The thermal deformation of magnetic poles can be affected by the material property of magnetic pole, the electric current of the coils, and the cooling effect of the lubricants and so on, so it belongs to the multiple physical field coupling. Therefore, the flow-solid-thermal coupled mathematics model of MLDSB is established and solved with ANSYS in this paper, and the distribution law of flow field of the magnetic pole is explored. The transfer path and distribution principles of heat loss are revealed and the distribution law of temperature rise and thermal deformation of magnetic pole in different operating conditions are explored. The results indicate that the temperature rise and thermal deformation of the stator is symmetrically distributed in the center, it gradually increase from the outside to the center, and the thermal deformation near the corner of magnetic pole is largest. The most heat loss can be taken away by the lubricants under the condition of heat
\end{abstract}

Jian-Hua Zhao

zhaojianhua@ysu.edu.cn

College of Civil Engineering and Mechanics, Yanshan University, Qinhuangdao 066004, China

2 Fluid Power Transmission and Control Laboratory, Yanshan University, Qinhuangdao 066004, China;

3 Jiangsu Provincial Key Laboratory of Advanced Manufacture and Process for Marine Mechanical Equipment, Zhenjiang 212003, China; balance. The thermal deformation of magnetic pole can increase linearly as the current gradually increase, and the stress is concentrated in the threaded hole and magnetic pole. The thermal deformation decreases linearly as the inlet pressure of the lubricants gradually increase. The PIV results of flow trace are basically consistent with the simulation results. The research in this paper can provide the theoretical reference for the structural design and the optimization of MLDSB.

Keywords: Magnetic-Liquid Double Suspension Bearing • Multiple physical field coupling • Temperature rise • Thermal deformation • Inlet pressure $\bullet$ Current

\section{Introduction}

The hydrostatic bearing is introduced into the magnetic suspension to form Magnetic Liquid Double Suspension Bearing (MLDSB). MLDSB is mainly supported by electromagnetic suspension and assisted by hydrostatic supporting, and then its bearing capacity and stiffness can be greatly improved. It's suitable for the occasions of medium speed, heavy load ${ }^{[1-2]}$.

MLDSB is composed of bracket, motor, coupling, multi-diameter shaft, journal bearing unit, axial bearing unit, journal loading motor, axial loading motor and so on as Fig.1.

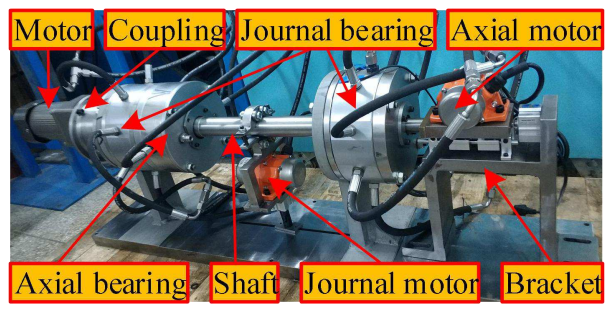

Fig.1 Magnetic Liquid Double Suspension Bearing 
The structure of MLDSB is shown as Fig.2 and Fig.3. Eight magnetic poles are symmetrically uniformly distributed on the stator, and each one is wrapped by the coil with the same number of turns. Due to the different wrapping manner, eight magnetic poles are distributed with the sequence of NSSNNSSN. The magnetic loop can form between two adjacent magnetic poles and the rotor, and then electromagnetic suspension force will produce. There is inlet hole in the magnetic pole, and the end face of magnetic pole is the hydrostatic bearing face. The hydraulic resistance can form when the lubricant flows through the gap between magnetic sleeve and magnetic pole, and then the hydrostatic force will produce in the end face of magnetic pole ${ }^{[3-4]}$.

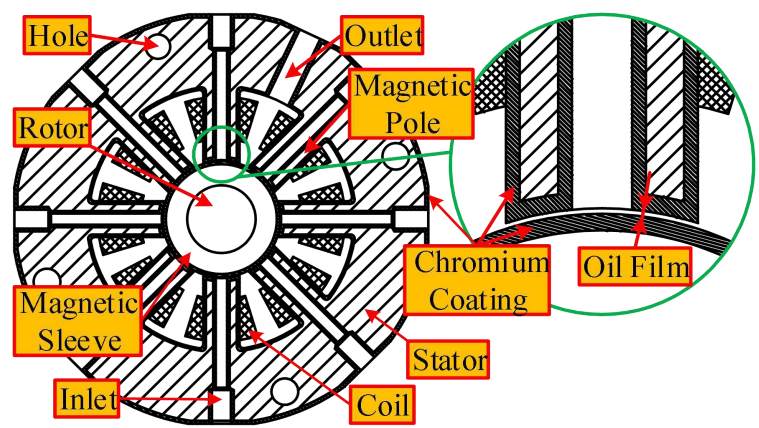

Fig.2 Sectional view of radial unit of MLDSB

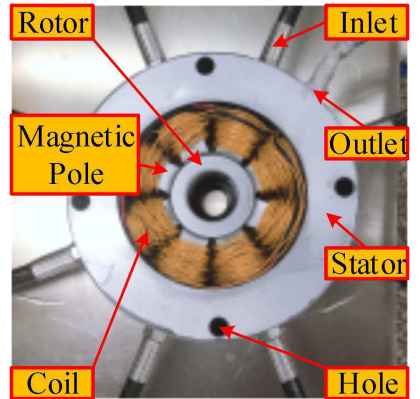

Fig.3 Photo of radial unit of MLDSB

The current of the electromagnetic system is in the real-time regulation state, so the great heat loss can be produced in the coils, and then the temperature rise and thermal deformation of magnetic pol will be presented. The gap between the magnetic pole and magnetic sleeve decreases, the coatings of magnetic pole and magnetic sleeve can be worn overly, and then the operation stability and service life of MLDSB will be reduced severely. So the heat loss and heat balance analysis are the key technology limitations affected the design and stability operation of MLDSB.
At present, many scholars made a deep research on the heat loss and heat balance of Active Magnetic Bearing (AMB), and had achieved the fruitful results.

Professor HU [5] researched experimentally the temperature field and the distribution law of radial magnetic suspension bearing.

Professor WANG ${ }^{[6]}$ calculated the heat loss of heavy load magnetic bearing in the energized state with Maxwell and then studied the temperature field distribution of the magnetic bearing by using Workbench software.

Professor YANG [7] studied the energy loss of electromagnetic bearings under rotating magnetic flux conditions, and expounded the calculation method of iron loss of magnetic materials. Furthermore, the energy loss of the HTR-PM primary helium circulator electromagnetic bearing was calculated based on the existing empirical formulas of copper loss, iron loss and wind friction loss.

Professor $\mathrm{ZHANG}{ }^{[8]}$ analyzed the temperature field of solid thrust electromagnetic bearing by using the software Maxwell 2D in order to keep the heat balance of the bearing system, reduce the eddy current loss, improve the temperature rise characteristics and the service life.

Professor XIE [9] designed the homopolar and heteropolar radial magnetic suspension bearings with the same performance parameters which was applied to the magnetic suspension bearing-rotor test system, and analyzed the effect on the support loss under different structures and current control models.

Professor LIU ${ }^{[10]}$ analyzed the magnetic field of the rotor of magnetic bearing with yoshimoto's radial magnetic suspension bearing model under the assumption of the linear magnetic permeability. Then the eddy-current loss of the rotor was estimated under the constant angular velocity harmonic magneto motive force, and the curve of the eddy-current loss change with rotational speed and the conductivity of rotor material are obtained.

Professor YANG [11] summarized the calculation methods of copper loss, iron loss and wind loss of active magnetic bearing at high speed, and gave the applicable range of the corresponding models.

Compare with the traditional AMB, there are three heat dissipation pathways in MLDSB as Fig.4. 


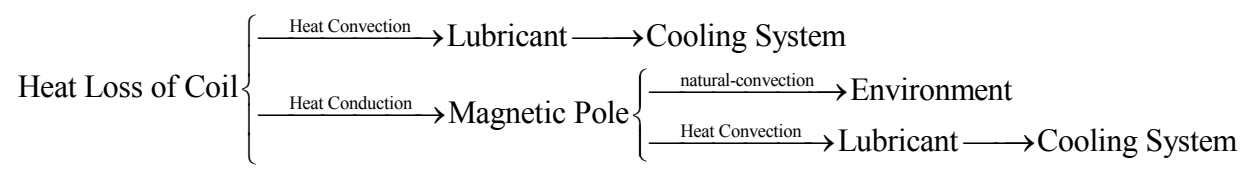

Fig.4 Heat dissipation pathways of MLDSB

The difference between the heats taken away by three dissipation pathways and the heat losses of the coil is the heat source of the temperature rise and thermal deformation of magnetic pole, and then it can lead to the over-wear of the coatings of magnetic poles and magnetic sleeve. At present, there are not the research on the temperature rise and thermal deformation of magnetic pole of MLDSB.

So the mathematical model of MLDSB is established in the paper, and the heat dissipation pathway and the distribution law of heat loss under multiple physical field coupling are presented. The internal effect law of temperature rise and thermal deformation of magnetic pole is analyzed, and it can provide the theoretical reference for the structural design and the optimization of MLDSB.

\section{Simulation model of MLDSB}

\subsection{Meshing and boundary condition}

The design parameters and material properties of MLDSB are shown in Tab. 1 and Tab. 2 respectively.

Tab.1 Design parameters of MLDSB

\begin{tabular}{cccc}
$\begin{array}{c}\text { Current } \\
i_{0} / \mathrm{A}\end{array}$ & $\begin{array}{c}\text { Initial feed } \\
\text { pressure } p_{0} / \mathrm{MPa}\end{array}$ & $\begin{array}{c}\text { Rotate speed } \\
n /(\mathrm{r} / \mathrm{min})\end{array}$ & $\begin{array}{c}\text { Cross-sectional area } \\
\text { of wire } S / \mathrm{mm}^{2}\end{array}$ \\
\hline 1.7 & 1 & 1000 & 0.7854 \\
\hline Wire diameter & Wire resistivity & Coil turns & Coil length \\
$D / \mathrm{mm}$ & $\rho_{0} /(\Omega / \mathrm{m})$ & $N /$ dimensionless & $L / \mathrm{m}$ \\
\hline 1.00 & 0.0224 & 236 & 22.75 \\
\hline Pole width & Pole length & Film thickness & $\mathrm{Viscosity}$ \\
$A / \mathrm{mm}$ & $B / \mathrm{mm}$ & $h_{0} / \mu \mathrm{m}$ & $\mu /(\mathrm{Pa} \bullet \mathrm{s})$ \\
\hline 20 & 45 & 30 & $4.136 \times 10^{-4}$ \\
\hline
\end{tabular}

Tab.2 Material properties of MLDSB

\begin{tabular}{cccccc}
\hline \multirow{2}{*}{ Type } & Density & Specific heat & Heat & Elasticity Dilatation \\
& $\rho\left(\mathrm{kg} / \mathrm{m}^{3}\right)$ & capacity $c$ & conductivity & modulus coefficient \\
& & $\left(\mathrm{J} / \mathrm{kg} /{ }^{\circ} \mathrm{C}\right)$ & $k\left(\mathrm{~W} / \mathrm{m} /{ }^{\circ} \mathrm{C}\right)$ & $E / \mathrm{MPa}$ & $\beta /\left(\mu \mathrm{m} /{ }^{\circ} \mathrm{C}\right)$ \\
\hline
\end{tabular}

\begin{tabular}{|c|c|c|c|c|c|c|}
\hline \multicolumn{2}{|c|}{ Stator 23QG385 } & \multirow{2}{*}{$\begin{array}{l}7650 \\
8978\end{array}$} & \multirow{2}{*}{502} & \multirow{2}{*}{$\frac{16.27}{387.6}$} & \multirow{2}{*}{$\frac{1.95 \times 10^{5}}{1.1 \times 10^{5}}$} & \multirow{2}{*}{$\frac{11.2}{18.5}$} \\
\hline Coil & $\mathrm{Cu}$ & & & & & \\
\hline Oil & LHM-46 ${ }^{\#}$ & 870 & 1880 & 0.12 & - & - \\
\hline
\end{tabular}

The computational domain of MLDSB is divided into fluid domain and solid domain. The simulation model of MLDSB is reasonably simplified to avoid the vast of finite element nodes ${ }^{[12]}$.

(1) Screw threads on inlet and outlet are ignored.

(2) Chamfering is assumed as right angle.

(3) Shaft shoulder on the rotor is ignored.

(4) End cover is ignored, and the contact face between lubricant and air is adiabatic surface.

Finally, the computational domain of MLDSB is meshed as Fig.5.

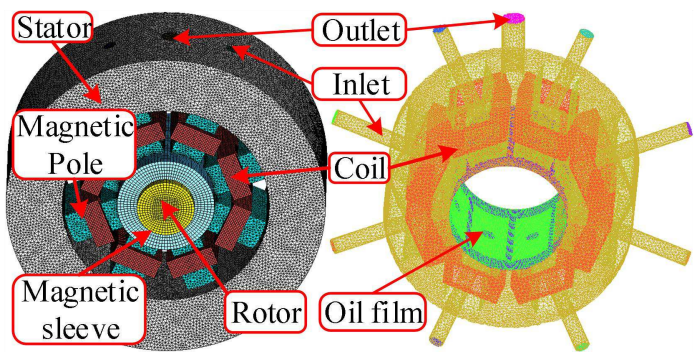
(a) Solid state grid
(b) Fluid state grid

Figure.5 Grid of calculation domain of MLDSB

Because of the heat exchange between stator, coil and lubricant, the temperature field is solved with the coupled heat transfer model in order to ensure the continuous heat transfer between coupling surfaces. The contact surface between fluid and solid is set as coupling surface, and then the heat transfer coefficient of the coupling surface is automatically solved in FLUENT [13,14]. The heat transfer surface of MLDSB is shown as Fig.6. 


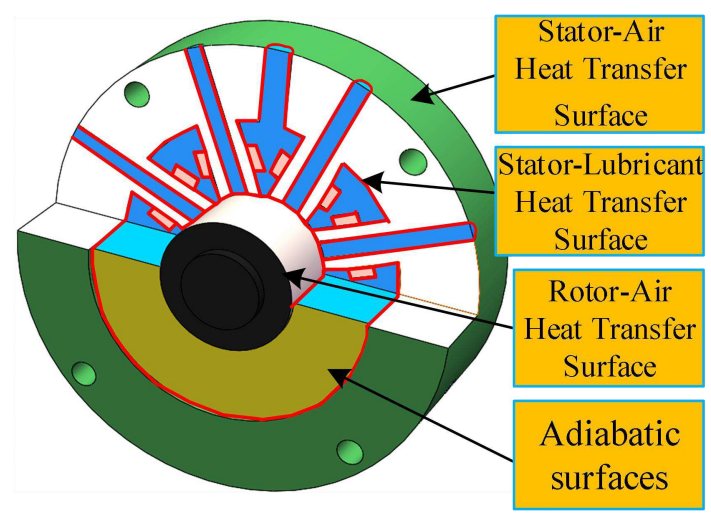

Fig.6 Heat transfer surface of MLDSB

(1) Heating loss of coil

The heating loss of the coil is calculated as Eq. ${ }^{[15]}$.

$$
\left\{\begin{array}{l}
P_{c u}=I^{2} R=I^{2} \rho L \\
q_{c u}=\frac{P_{c u}}{V_{c u}}=\frac{I^{2} \rho}{S}
\end{array}\right.
$$

Where $P_{c u}$ Heating power of coil, W;

I-Input current, A;

$R-$ Resistance of coil, $\Omega$;

$L$ - Length of coil, m;

$\rho-$ Resistivity of coil, $\Omega / \mathrm{m}$.

$q_{c u}-$ Heat generation rate of coil, $\mathrm{W} / \mathrm{m}^{3}$;

$V_{c u}-$ Volume of coil, $\mathrm{m}^{3}$;

$S$-Area of coil, $\mathrm{m}^{2}$.

The heating power of single coil is $1.47 \mathrm{~W}$ when the current is $1.7 \mathrm{~A}$, and then heat generation rate is 824 $\mathrm{KW} / \mathrm{m}^{3}$.

(2) Heat transfer between rotor and air

When the rotor rotates, the convective heat transfer coefficient between the rotor end and air can be calculated as follows ${ }^{[16]}$ :

$$
h_{1}=7.8 u^{0.78}=7.8 \times\left(\frac{\pi r n}{40}\right)^{0.78}
$$

Where $h_{1}-$ Heat transfer coefficient between rotor and air, $\mathrm{W} /\left(\mathrm{m}^{2} \cdot{ }^{\circ} \mathrm{C}\right)$;

$u$ - Linear velocity of rotation axis, $\mathrm{m} / \mathrm{s}$;

$r$-Rotation radius, $\mathrm{m}$;

$n-$ Rotation speed of rotor, $\mathrm{r} / \mathrm{min}$;

The heat transfer coefficient between the rotor and air is $h_{1}=22.66 \mathrm{~W} /\left(\mathrm{m}^{2} \cdot{ }^{\circ} \mathrm{C}\right)$ when the rotation speed is $n=1000 \mathrm{r} / \mathrm{min}$.

(3) Heat transfer between stator, lubricant and air

The heat transfer between stator and air is the combined form of natural convection and radiation heat transfer. According to Reference [17], the heat transfer coefficient between rotor and air is $h_{2}=9.7 \mathrm{~W} /\left(\mathrm{m}^{2} \cdot{ }^{\circ} \mathrm{C}\right)$.

\section{Temperature rise and thermal deformation of MLDSB}

According to the parameters in Tab.1 and Tab.2, the heat loss of the coils in Eq.2 is taken as the heat source of MLDSB in order to simulate the fluid-solid heat coupling of bearing system with ANSYS software. The boundary conditions can be shown as follows: Current is $1.7 \mathrm{~A}$, pressure is $1.0 \mathrm{MPa}$, environment and lubricant temperature is $25^{\circ} \mathrm{C}$.

\subsection{Analysis of bearing temperature field}

The temperature of MLDSB is distributed symmetrically in the center. The largest temperature rise occurs near the coil and magnetic pole, and it decreases to the environmental temperature along the radius direction as Fig.7. As the heat transfer of the outlet, forced fluid convection is better than natural convection, so the temperature of the outlet is slightly lower than the other parts.

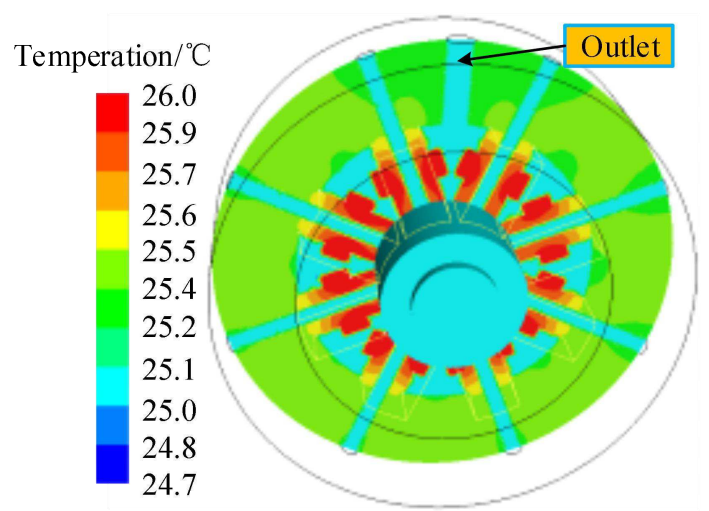

Fig.7 Cloud chart of temperature of MLDSB

According to Fig.7, when the current is $1.7 \mathrm{~A}$, the average temperatures of the coil, the stator, the rotor, the flux sleeve, the inlet and the outlet are respectively $25.94^{\circ} \mathrm{C}, \quad 25.40^{\circ} \mathrm{C}, \quad 25.33^{\circ} \mathrm{C}, \quad 25.33^{\circ} \mathrm{C}, \quad 25.0^{\circ} \mathrm{C}$ and $25.08^{\circ} \mathrm{C}$

\subsection{Analysis of flow state of lubricant}

Fig.8 Fig.10 is velocity cloud-chart, flow 
vector-chart and partial vector-chart of MLDSB.

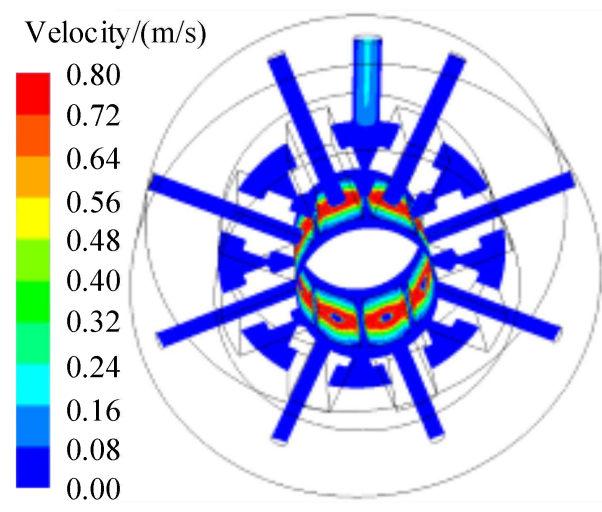

Fig.8 Cloud chart of velocity of MLDSB

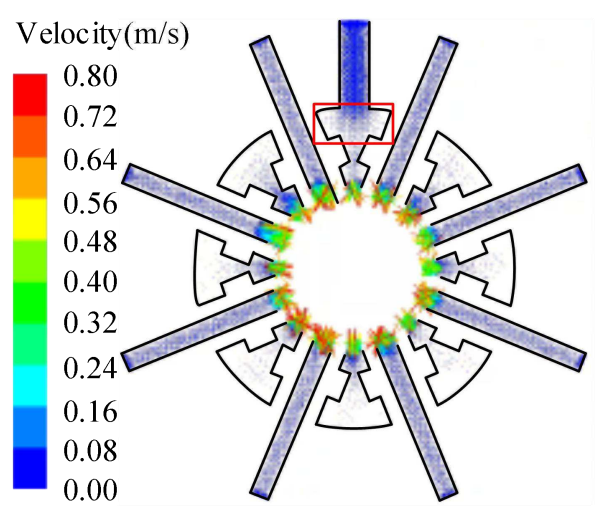

Fig.9 Flow vector-chart of MLDSB

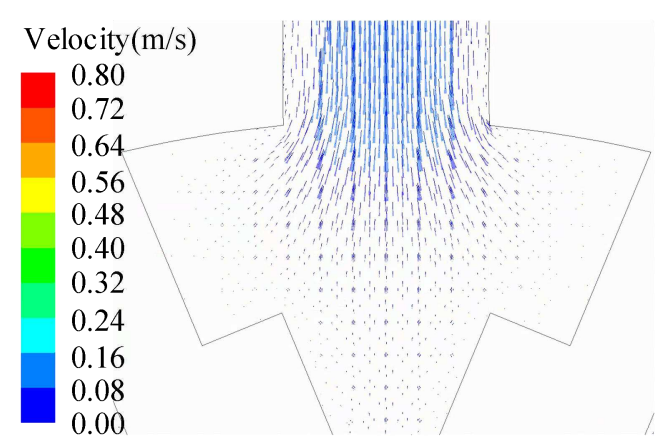

Fig.10 Partial flow vector-chart of MLDSB

The lubricant flows quickly through the small gap between the magnetic pole and the rotor while slowly in other parts. The flow field is uniform without the vortex and the cooling effect is great when it flows through the coil as Fig. $8 \sim$ Fig. 10 .

The pressure and lubricant of inlet hole can be presented as Fig. 11.

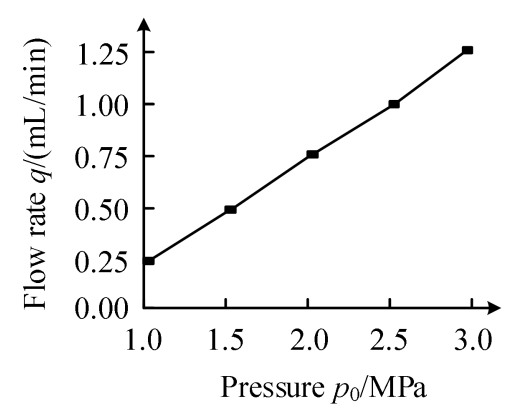

Fig.11 Curse between pressure and flow rate

According to Fig.11, the flow rate of the lubricant increases linearly with the increase of the pressure of the inlet.

\subsection{Heat distribution law of coil}

The heat transfer rates of fluid-solid surface and solid-solid surface are extracted and the distribution rule of coil heat loss is presented as Fig. 12.

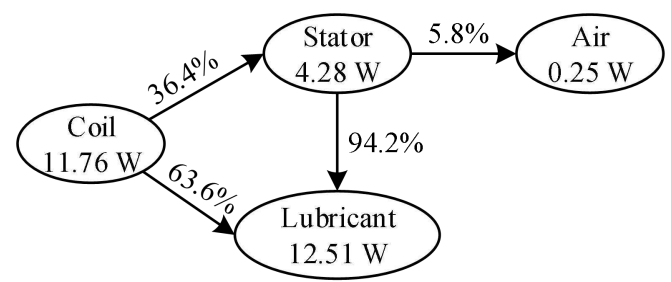

Fig.12 Heat transfer rate and ratio between surfaces

According to Fig.12, when MLDSB reaches thermal balance, the heat loss of coil is up to $11.76 \mathrm{~W}$, of which $7.48 \mathrm{~W}(63.6 \%)$ carried away by lubricant through convection heat transfer, and $4.28 \mathrm{~W}$ (36.4\%) absorbed by stator through heat conduction. Meanwhile $0.25 \mathrm{~W}$ $(5.8 \%)$ of the stator heat is emitted to the air, $4.03 \mathrm{~W}$ (94.2\%) absorbed by the lubricant.

Therefore, as the maximum heat dissipation path, the lubricant can absorb $11.51 \mathrm{~W}$ heat loss $(97.9 \%)$ of the coil while the others are absorbed by air.

\subsection{Thermal deformation analysis of stator}

The thermal deformation of the stator can be presented as Fig.13. 


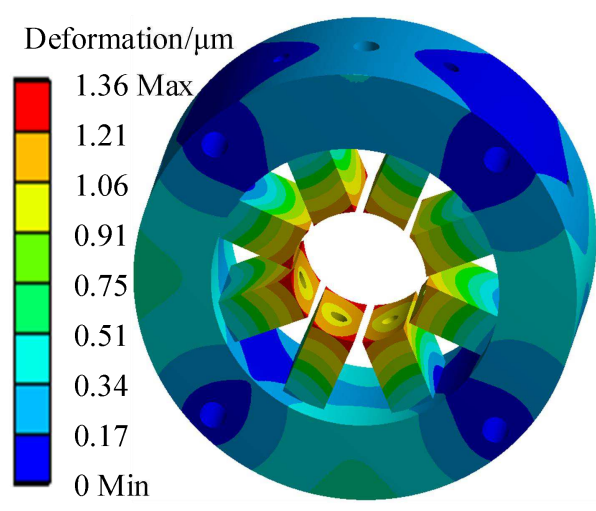

Fig.13 Cloud chart of thermal deformation of stator

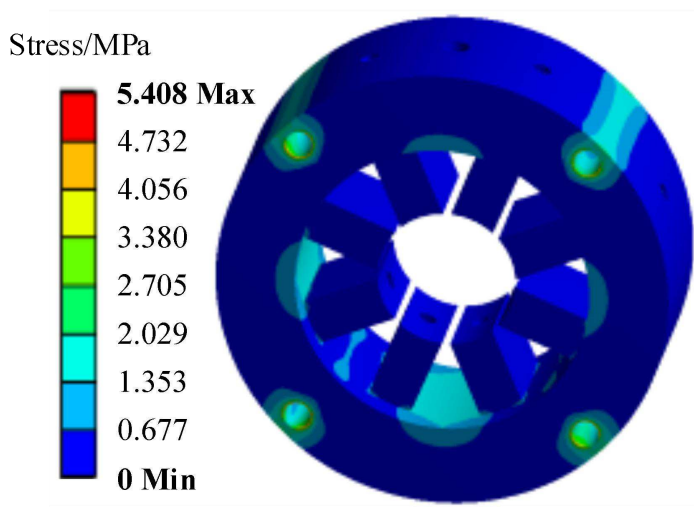

Fig.15 Cloud chart of stress of stator
According to Fig.13, the stator deformation is distributed symmetrically in the center. And it accumulates to a maximum of $1.36 \mu \mathrm{m}$ at the top corner of magnetic pole. Due to the constraint of four threaded holes, the deformation at screw threaded hole is zero.

The thermal deformation of end face of magnetic pole is presented as Fig.14.

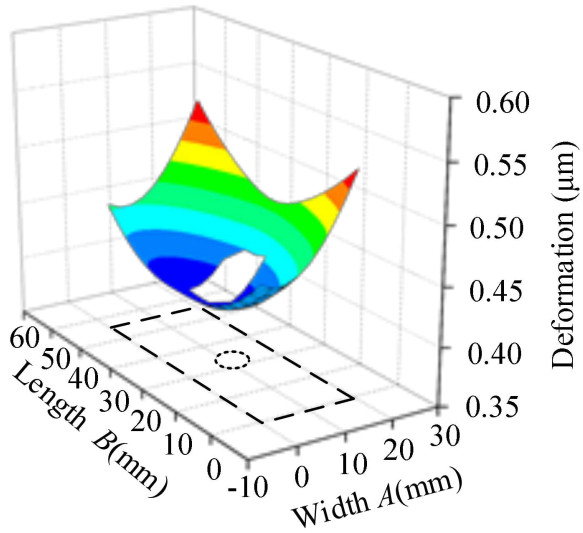

Fig.14 peak diagram of thermal deformation of magnetic pole

According to Fig.14, the thermal deformation increases gradually from the center to the surrounding. Because of contacting with the lubricant directly, the cooling effect of the inlet is great and the thermal deformation is $0.409 \mu \mathrm{m}$. The right corner of magnetic pole is the farthest from the inlet, and then its deformation is the largest $(0.540 \mu \mathrm{m})$. The average value of magnetic pole is $0.453 \mu \mathrm{m}$.

\subsection{Thermal stress analysis of stator}

The thermal stress of the stator is presented as Fig. 15.
According to Fig.15, due to the restriction of screw threaded holes, the shell uplifts, and the magnetic poles attracted each other, and then the maximum stress of the screw thread and the middle position of the magnetic pole increases to $5.408 \mathrm{MPa}$.

\section{Effect of operation parameter on thermal}

\section{deformation of magnetic pole}

\subsection{Effect of current on temperature}

The temperature of each part of MLDSB is presented as the current increases gradually as Fig.16.

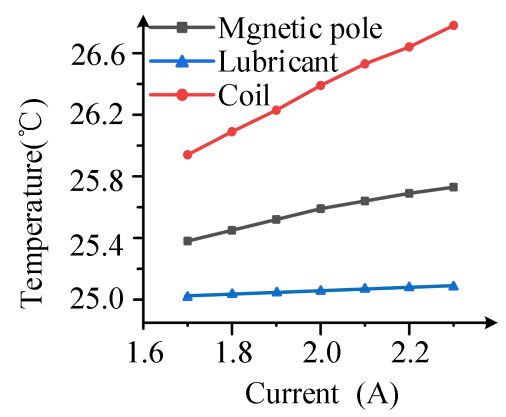

Fig.16 Curves between current and temperature of MLDSB

According to Fig.16, the average temperatures of magnetic pole, coil and lubricant increase linearly as the current increases. The temperature rise of coil is the most obvious $\left(25.96^{\circ} \mathrm{C} \rightarrow 26.78^{\circ} \mathrm{C}\right)$, followed by that of magnetic pole $\left(25.40^{\circ} \mathrm{C} \rightarrow 25.72^{\circ} \mathrm{C}\right)$. The temperature rise of lubricant $\mathrm{s}$ the minimum $\left(25.02^{\circ} \mathrm{C} \rightarrow 25.05^{\circ} \mathrm{C}\right)$ because of the continuous cooling effect and the smaller specific heat capacity of the lubricant.

\subsection{Effect of current on heat distribution of coil}

The heat transfer rates between coil/lubricant and 
coil/stator are presented as Tab.3 as current increases successively.

Tab.3 Heat transfer rate between coil/lubricant/stator

\begin{tabular}{|c|c|c|c|c|c|}
\hline $\begin{array}{l}\text { Current } \\
\text { (A) }\end{array}$ & $\begin{array}{l}\text { Coil } \\
\text { loss } \\
\text { (W) }\end{array}$ & $\begin{array}{l}\text { Heat transfer } \\
\text { of } \\
\text { Coil/lubricant } \\
\text { rate (W) }\end{array}$ & $\begin{array}{l}\text { Ratio } \\
(\%)\end{array}$ & $\begin{array}{c}\text { Heat transfer } \\
\text { of } \\
\text { Coil/stator } \\
\text { rate (W) }\end{array}$ & $\begin{array}{c}\text { Ratio } \\
(\%)\end{array}$ \\
\hline $1.7 \mathrm{~A}$ & 11.76 & 7.48 & $63.6 \%$ & 4.28 & $36.4 \%$ \\
\hline $1.8 \mathrm{~A}$ & 13.22 & 8.43 & $63.4 \%$ & 4.79 & $36.6 \%$ \\
\hline $1.9 \mathrm{~A}$ & 14.05 & 8.84 & $62.9 \%$ & 5.21 & $37.1 \%$ \\
\hline $2.0 \mathrm{~A}$ & 16.34 & 10.30 & $63.0 \%$ & 6.04 & $37.0 \%$ \\
\hline $2.1 \mathrm{~A}$ & 17.99 & 11.34 & $63.0 \%$ & 6.65 & $37.0 \%$ \\
\hline $2.2 \mathrm{~A}$ & 19.74 & 12.40 & $62.8 \%$ & 7.34 & $37.2 \%$ \\
\hline $2.3 \mathrm{~A}$ & 21.58 & 13.55 & $62.8 \%$ & 8.03 & $37.2 \%$ \\
\hline
\end{tabular}

According to Tab.3, the coil loss increases by $83.5 \%$ $(11.76 \mathrm{~W} \rightarrow 21.58 \mathrm{~W})$, and the heat transfer rate between coil and lubricant increases by $82.9 \%(7.41 \mathrm{~W} \rightarrow 13.55 \mathrm{~W})$ and then which between the coil and stator increases by $84.6 \%(4.35 \mathrm{~W} \rightarrow 8.03 \mathrm{~W})$ as the current increases successively.

The heat transfer rate between coil and lubricant decreases $(63.6 \% \rightarrow 62.8 \%)$ and which between coil and stator increases $(36.4 \% \rightarrow 37.2 \%)$, and then the cooling efficiency of the lubricant decreases as the current increases successively.

\subsection{Effect of current on thermal deformation of stator}

Fig.17 is a diagram of maximum thermal deformation of stator.

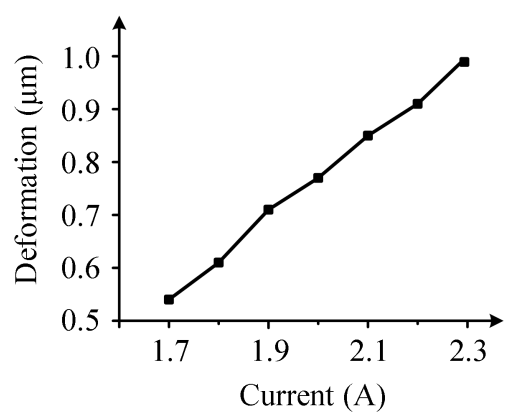

Fig.17 Curves between current and deformation of MLDSB

According to Fig.17, the maximum thermal deformation of stator increases linearly from $0.54 \mu \mathrm{m}$ to
$0.997 \mu \mathrm{m}$ when the current increases from 1.7 A to 2.3 A.

\subsection{Effect of pressure on temperature of magnetic pole}

As the input pressure increases successively, temperature of MLDSB can be shown as Fig.18.

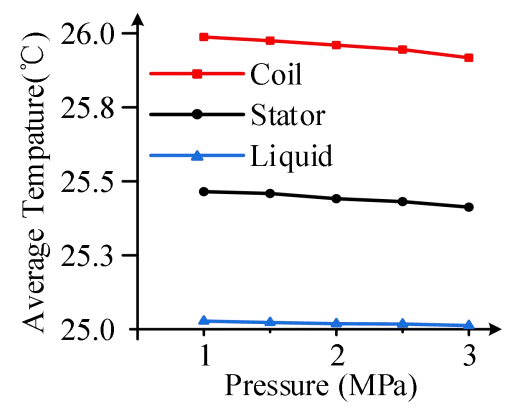

Fig.18 Curves between pressure and temperature of MLDSB

According to Fig.18, the average temperature of MLDSB gradually decreases with the increase of inlet pressure, the cooling effect of the coil is the most remarkable $\left(25.96^{\circ} \mathrm{C} \rightarrow 25.87^{\circ} \mathrm{C}\right)$, followed by the stator $\left(25.40^{\circ} \mathrm{C} \rightarrow 25.36^{\circ} \mathrm{C}\right)$. The temperature of the lubricant still has no significant change $\left(25.02^{\circ} \mathrm{C} \rightarrow 25.01^{\circ} \mathrm{C}\right)$.

\subsection{Effect of pressure on heat distribution of coil}

As the inlet pressure increases successively, the ratio of heat transfer rate between coil/lubricant and coil/stator can be shown as Fig. 19.

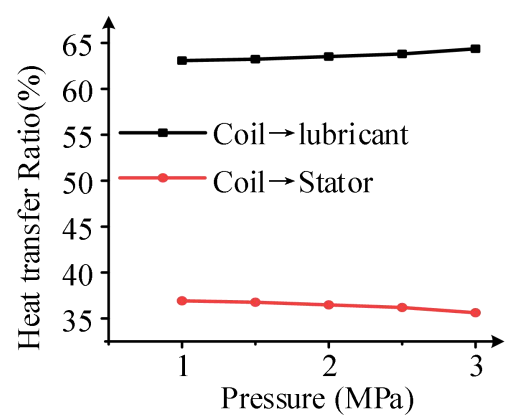

Fig.19 Effect of pressure on heat distribution law

According to Fig.19, the heat loss which is taken away by the lubricant increases from $63.6 \%$ to $64.9 \%$ with the increase of inlet pressure from $1 \mathrm{MPa}$ to $3 \mathrm{MPa}$. The cooling efficiency of lubricant can be improved and the temperature rise of MLDSB can be reduced effectively.

\subsection{Effect of pressure on deformation of stator}

The variation law between the thermal deformation of stator and inlet pressure can be shown as Fig.20. 


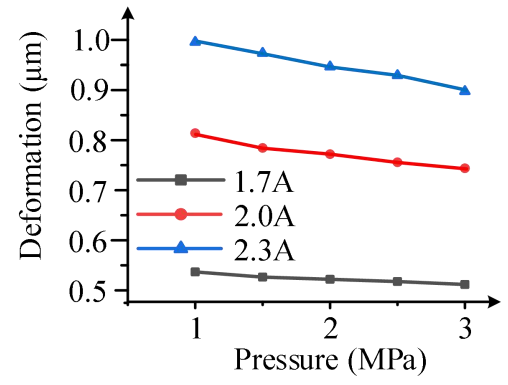

Fig.20 Curves between pressure and thermal deformation

According to Fig.20, the thermal deformation of the stator decreases gradually and the cooling efficiency is improved with the increase of the inlet pressure. The thermal deformation decreases by $5.56 \%(0.54 \mu \mathrm{m} \rightarrow 0.51$ $\mu \mathrm{m})$ at the current is $1.7 \mathrm{~A}$ when the pocket pressure increased from $1 \mathrm{MPa}$ to $3 \mathrm{MPa}$. The thermal deformation decreases by $8.98 \%(0.813 \mu \mathrm{m} \rightarrow 0.74 \mu \mathrm{m})$ and by $9.53 \%(0.997 \mu \mathrm{m} \rightarrow 0.902 \mu \mathrm{m})$ when the current is $2.0 \mathrm{~A}$ and $2.3 \mathrm{~A}$ respectively.

\section{Measure system and result analysis}

\subsection{PIV measure system}

PIV measure system is composed of pulse transmitter, light arm, CCD camera, synchronizer, frame receiver, tracer particle system, frame trap, simulation software and so on ${ }^{[18]}$, and its principle and connected relation are respectively shown as Fig.21 and Fig.22.

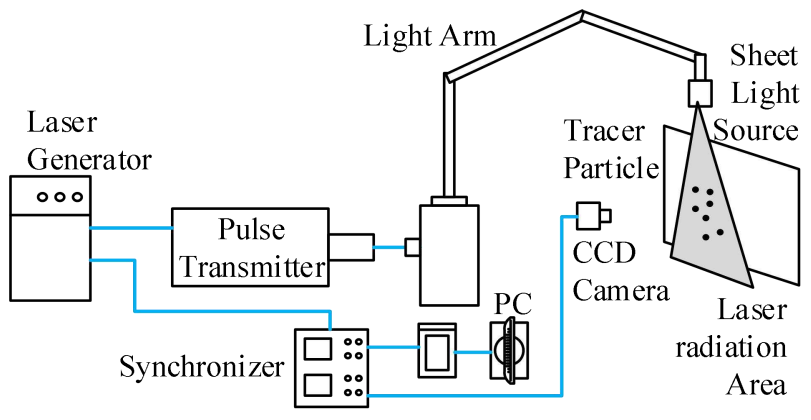

Fig.21 Composition and principle of PIV measure system

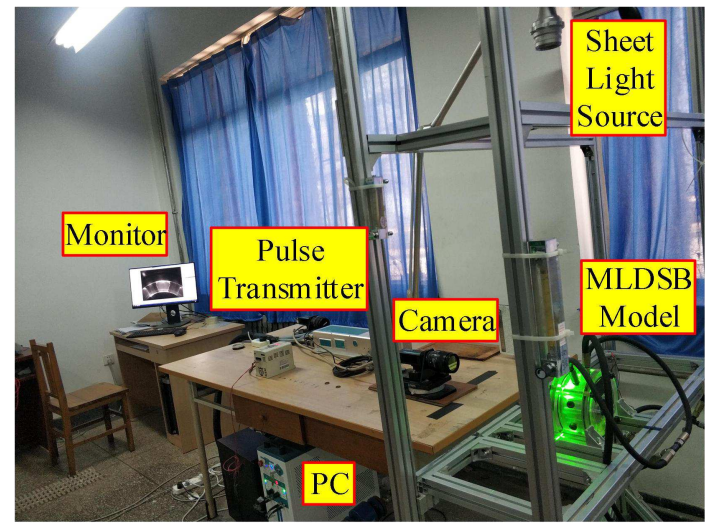

Fig.22 Photo of PIV measure system

The model of pulse transmitter is Vlite-200, and its parameters can be shown as Tab.4.

Tab.4 Parameters of pulse transmitter

\begin{tabular}{cccc}
\hline Model & Supply voltage & Wavelength & Energy \\
\hline Vlite-200 & $220 \mathrm{~V}$ & $532 \mathrm{~nm}$ & $200 \mathrm{~mJ}$ \\
\hline Frequency & Pulse width & Stability & Launching angle \\
\hline $1 \sim 15 \mathrm{~Hz}$ & $\leq 8 \mathrm{~ns}$ & $\leq 2 \%$ & $\leq 3 \mathrm{mrad}$ \\
\hline
\end{tabular}

\subsection{Lubricant Supply System of MLDSB}

For the sake of observing the position of the tracing particles ${ }^{[19-20]}$, the water is taken as the lubricant of PIV measure system.

The lubricant supply system is composed of pump, flow gauge, throttle valve, pressure gauge, water tank and so on as Fig.23.

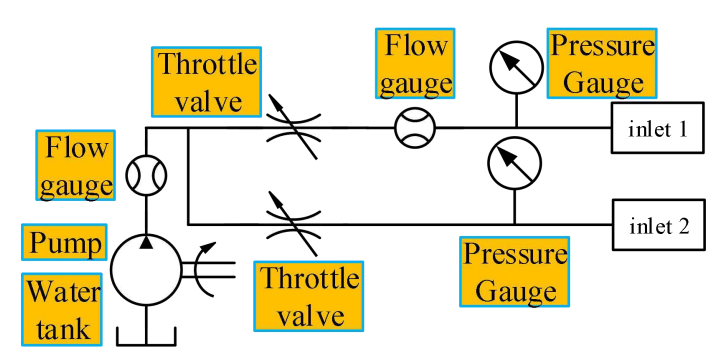

Fig.23 Lubricant supply system of MLDSB

The key parameters of components can be shown as follows:

(1) Needle valve, model: J13W-160P, diameter: $6 \mathrm{~mm}$, material: Stainless steel 304.

(2) Pump, model: QDX1.5-15-0.37, head: $15 \mathrm{~m}$, rated 
power: $0.37 \mathrm{~kW}$.

(3) Pressure gauge, range: $0.02 \sim 0.6 \mathrm{MPa}$.

(4) Flow gauge, model: HSBG-F8500A10131, media: water, range: $0.0283 \sim 205258 \mathrm{~m}^{3} / \mathrm{h}$.

\subsection{Model of journal bearing unit}

Model of journal bearing unit is composed of stator (organic glass), skeleton seal, rotor (organic glass), end cap (organic glass), magnetic sleeve (organic glass), cover (organic glass) and so on as Fig.24.

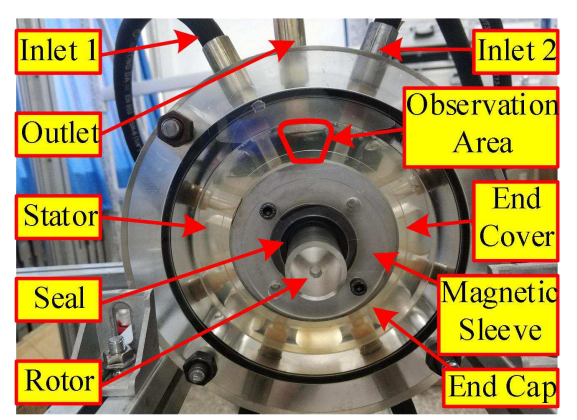

Fig.24 Model of journal bearing unit of MLDSB

The stator model of MLDSB can be shown as Fig.25, and its parameters are shown in Tab.5.

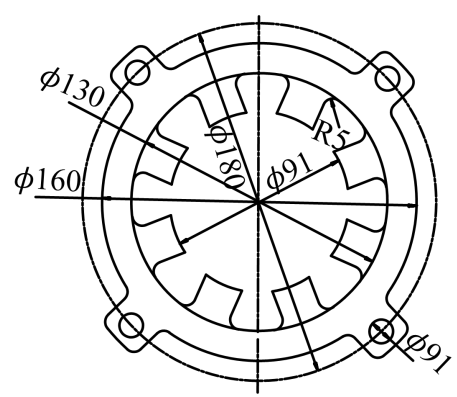

Fig.25 Stator model of MLDSB

Tab.5 Parameters of stator model of MLDSB

\begin{tabular}{cccc}
\hline $\begin{array}{c}\text { Width of magnetic } \\
\text { pole } A\end{array}$ & $\begin{array}{c}\text { Length of } \\
\text { magnetic pole } B\end{array}$ & $\begin{array}{c}\text { Area of magnetic } \\
\text { pole } S_{1}\end{array}$ & $\begin{array}{c}\text { Area of } \\
\text { coil-pocket } S\end{array}$ \\
\hline $20 \mathrm{~mm}$ & $45 \mathrm{~mm}$ & $887.8 \mathrm{~mm}^{2}$ & $437.1 \mathrm{~mm}^{2}$ \\
\hline
\end{tabular}

\subsection{Experimental step of flow field test of MLDSB}

The lubricant with tracing particles can flow into MLDSB model through inlet 1 and inlet 2. The flow rate of the lubricant can be regulated by throttle valve and measured by the flow gauge at the entrance, and the pressure is measured by pressure gauge at the entrance.

The pressure of the lubricant at inlet 1 and inlet 2 can be shown as Tab.6.

Tab.6 Pressure of lubricant at inlet 1 and inlet 2

\begin{tabular}{ccccccc}
\hline Number & 1 & 2 & 3 & 4 & 5 & 6 \\
\hline Inlet 1 $(\mathrm{MPa})$ & 0.04 & 0.04 & 0.06 & 0.06 & 0.08 & 0.10 \\
& & & & & & \\
Inlet 2 $(\mathrm{MPa})$ & 0.00 & 0.04 & 0.00 & 0.06 & 0.08 & 0.10 \\
\hline
\end{tabular}

\subsection{Experimental result of pressure and flow rate of} lubricant

Due to the difference of experimental model and theoretical model of MLDSB, the parameters of experimental model are imported into Fluent software, and then the pressure and flow rate of lubricant at inlet 1 and inlet 2 can be measured as Tab.7, Fig.26 Fig.28.

Tab.7 Simulation and experimental result of flow rate

\begin{tabular}{|c|c|c|c|c|c|c|c|}
\hline & Number & 1 & 2 & 3 & 4 & 5 & 6 \\
\hline \multirow{4}{*}{ Inlet 1} & Pressure (MPa) & 0.04 & 0.04 & 0.06 & 0.06 & 0.08 & 0.10 \\
\hline & $\begin{array}{c}\text { Experimental } \\
\text { flow rate }(\mathrm{L} / \mathrm{min})\end{array}$ & 0.817 & 0.833 & 1.233 & 1.217 & 1.650 & 2.083 \\
\hline & Simulation & & & & & & \\
\hline & flow rate $(\mathrm{L} / \mathrm{min})$ & 0.883 & 0.883 & 1.333 & 1.333 & 1.767 & 2.217 \\
\hline \multirow{3}{*}{ Inlet 2} & Pressure (MPa) & 0.00 & 0.04 & 0.00 & 0.06 & 0.08 & 0.10 \\
\hline & $\begin{array}{c}\text { Experimental } \\
\text { flow rate }(\mathrm{L} / \mathrm{min})\end{array}$ & 0.000 & 0.800 & 0.000 & 1.183 & 1.633 & 2.033 \\
\hline & $\begin{array}{l}\text { Simulation } \\
\text { flow rate }(\mathrm{L} / \mathrm{min})\end{array}$ & 0.000 & 0.883 & 0.000 & 1.333 & 1.767 & 2.217 \\
\hline \multicolumn{2}{|c|}{ Total experimental } & 0.817 & 1.633 & 1.233 & 2.400 & 3.283 & 4.116 \\
\hline \multicolumn{2}{|c|}{ Total simulation } & 0.883 & 1.766 & 1.333 & 2.666 & 3.534 & 4.434 \\
\hline
\end{tabular}

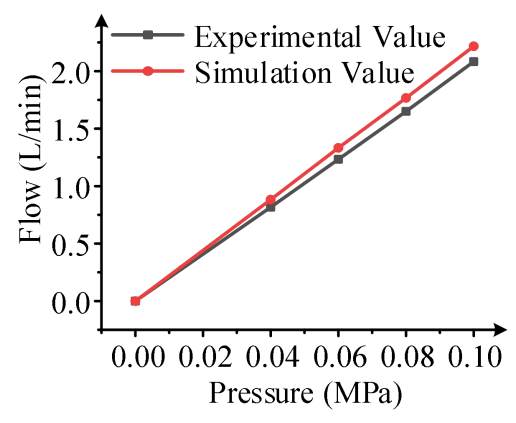


Fig.26 Simulation and experimental result of flow rate

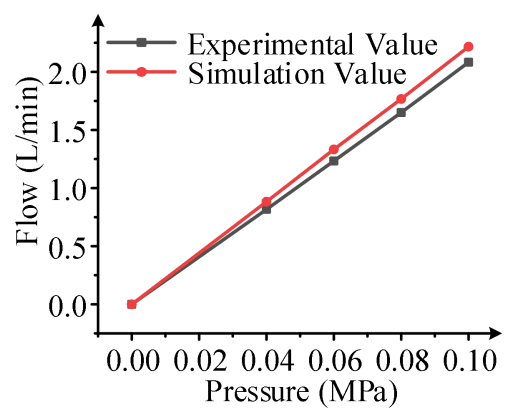

Fig.27 Simulation and experimental result of flow rate

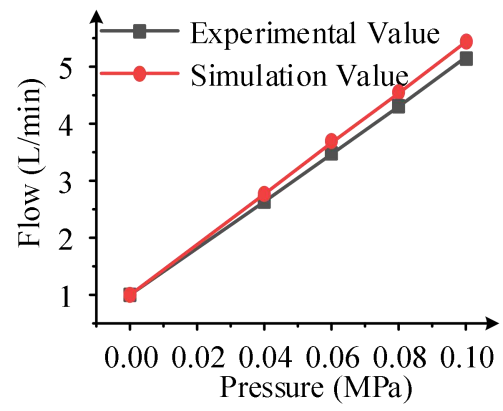

Fig.28 Simulation and experimental result of total flow rate

According to Fig.26 Fig.28, the experimental result and simulation result of flow rate both increase as the pressure of lubricant increases, and the range and tendency are same basically. Due to the poor machining accuracy of inner hole of the stator and action of gravity of the rotor, the simulation result is $8.2 \%$ greater than the experimental result.

\subsection{PIV result of flow trace of MLDSB}

The flow state of the lubricant can be measured with PIV measure system. Due to the difference of experimental model and theoretical model of MLDSB, the parameters of experimental model are imported into Fluent software, and then the flow trace of lubricant can be presented as Fig. $29 \sim$ Fig. 33 .

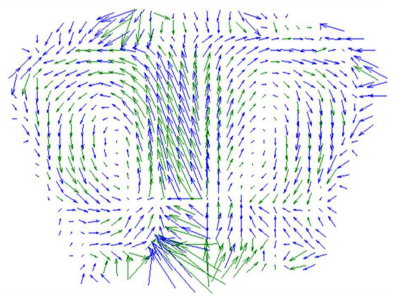

(a) PIV result

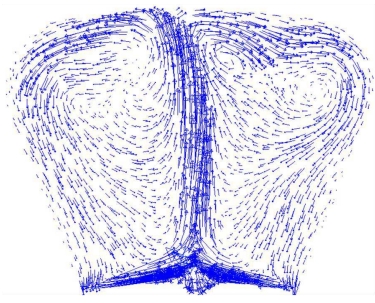

(b) Fluent result
Fig.29 Trace when inlet 1 and inlet 2 are $0.04 \mathrm{MPa}$

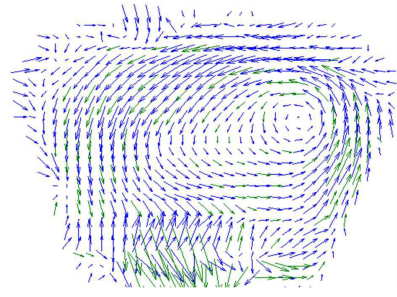

(a) PIV result

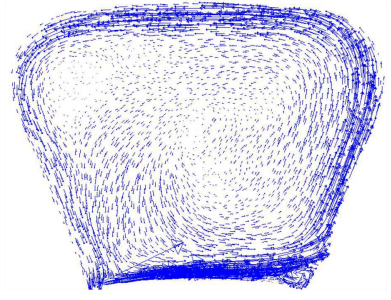

(b) Fluent result
Fig.30 Trace when inlet 1 is $0.04 \mathrm{MPa}$ and inlet 2 is $0 \mathrm{MPa}$

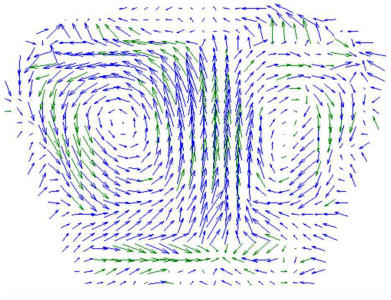

(a) PIV result

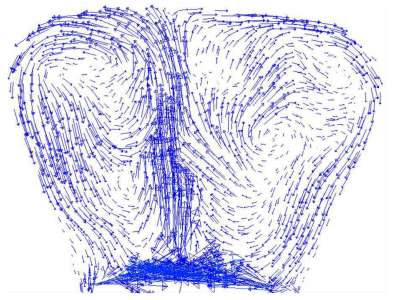

(b) Fluent result
Fig.31 Trace when inlet 1 and inlet 2 are $0.06 \mathrm{MPa}$

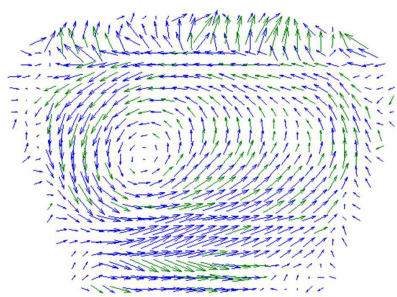

(a) PIV result

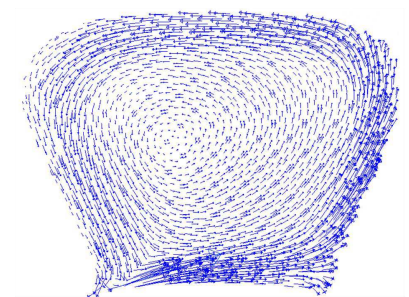

(b) Fluent result
Fig.32 Trace when inlet 1 is $0.06 \mathrm{MPa}$ and inlet 2 is $0 \mathrm{MPa}$

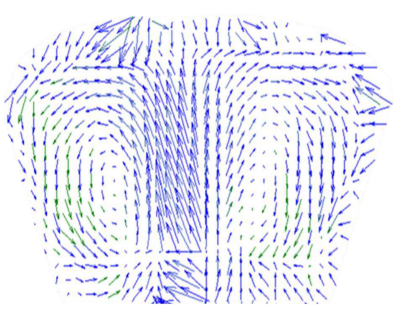

(a) PIV result

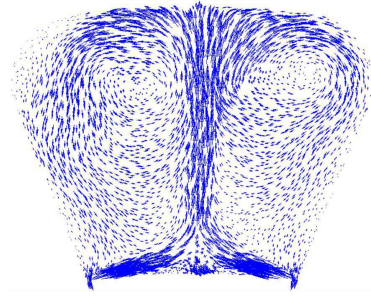

(b) Fluent result
Fig.33 Trace when inlet 1 and inlet 2 are $0.08 \mathrm{MPa}$

According to Fig. $27 \sim$ Fig. 31 , the PIV results of flow trace are basically consistent with the simulation results. When the pressure of inlet 1 and inlet 2 are both 0.04 $\mathrm{MPa}, 0.06 \mathrm{MPa}$ and $0.08 \mathrm{MPa}$, there are two whirlpools inside the stator, and the lubricant in the midpoint of the line between the centers of two whirlpools flows upward. When inlet 1 is only opened, there is one whirlpools inside the stator and its position is random. As the 
pressure increases, the tendencies of the flow traces are basically same.

The coil models are added into the PIV measure system, and the flow trace of the lubricant can be shown as Fig.34.

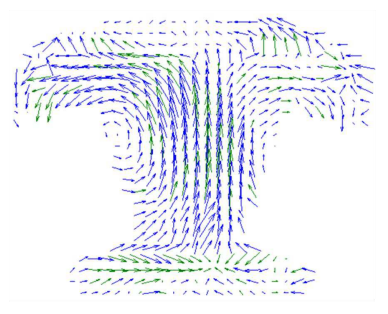

(a) PIV result

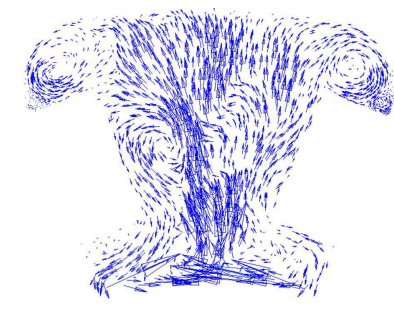

(b) Fluent result
Fig.34 Trace with coil model when inlet 1 and inlet 2 are 0.04 $\mathrm{MPa}$

According to Fig.34, PIV results of flow trace are basically consistent with simulation results. When the pressure of inlet 1 and inlet 2 are both $0.04 \mathrm{MPa}$, there are the whirlpools on the top left corner and the top right corner and near the coil, and then the lubricant flows upward in the middle area.

\section{Conclusion}

(1) The temperature rise and thermal deformation of the stator is symmetrically distributed in the center and gradually increase from the outside to the center, and then the thermal deformation near the corner of magnetic pole is largest.

(2) The most heat loss can be taken away by the lubricants under the condition of heat balance.

(3) As the current increases, the temperature of coils increase, the cooling efficiency decreases, and the thermal deformation of magnetic pole increases linearly, and the stress is concentrated in the threaded hole and the middle of the magnetic pole.

(4) As the inlet pressure increases, the cooling efficiency increases and the temperature rise and thermal deformation of magnetic pole can be decreases.

(5) The PIV results of flow trace are basically consistent with the simulation results, and then the correctness of the simulation idea and result can be verified.

\section{Declaration}

\section{Funding}

Supported by the National Natural Science Foundation of China (Grant No. 51705445), the Open Project Funding of Jiangsu Provincial Key Laboratory of Advanced Manufacture and Process for Marine Mechanical Equipment.

\section{Availability of data and materials}

The datasets supporting the conclusions of this article are included within the article.

\section{Authors' contributions}

The author' contributions are as follows: Jian-Hua Zhao in charge of the whole trial; Ji-Sheng Zhao wrote the manuscript; Ji-Sheng Zhao, Sheng Li, Zhe Wang, Dian-Rong Gao and Guo-Jun Du were assisted with sampling and laboratory analyses.

\section{Competing interests}

The authors declare no competing financial interests.

\section{Consent for publication}

Not applicable

\section{Ethics approval and consent to participate}

Not applicable

\section{Reference}

[1] J H ZHAO, Q WANG, B ZHANG, et al. Influence of Liquid Film Thickness on Static Property of Magnetic-Liquid Double Suspension Bearing [C]. International Conference on Intelligent and Interactive Systems and Applications, June, 17-18, Beijing, China, 2017: 809-816.

[2] J H ZHAO, B ZHANG, T CHEN, et al. Influence of Liquid Film Thickness on Bearing Characteristics of Magnetic-Liquid Suspension Guide-way [J], Journal of Engineering, 2018, (10): 2-9.

[3] J H ZHAO, D G GAO, Q WANG. Effect of Film Thickness on Load-Carrying Property of Seawater Dynamic-Hydrostatic Hybrid Thrust Bearing [C]. International Conference on Intelligent and Interactive Systems and Applications, June, 25-26, Shanghai, China, 2016: 59-65.

[4] J H ZHAO, B ZHANG, T CHEN, et al. Influence of Liquid Film Thickness on Bearing Characteristics of Magnetic-Liquid Suspension Guide-way [J], Journal of Engineering, 2019, 32(01): 66, 01-14.

[5] L XIN, H C WU. Analysis and Calculation of Temperature Field of Radial Magnetic Bearing [J]. Machinery, 2011, 49(6):18-21. (in Chinese)

[6] F L JIE, W M WANG, B B LIU. Analysis and Optimization of Heavy-Load Magnetic Bearings in Mechanics and Thermal Characteristics [J]. Chinese Journal of Turbomachinery, 2018, 60(04): 62-68. (in Chinese)

[7] P C WU. Calculation and Analysis of Electromagnetic Bearing Energy Loss of HTR-PM Main Helium Fan [D]. Beijing: Qinghua University, 2014. (in Chinese)

[8] Y WANG, Z P ZHANG, Y SUN, et al. Temperature Field Analysis of Solid Thrust Electromagnetic Bearing based on Breeze Power Generation [J]. Chinese and Foreign Entrepreneurs, 2013, (14): 233-234. (in Chinese)

[9] Z Y XIE, K F WU, Q C SHI, et al. Experimental Analysis of Influence of Homoppole Structure and Zero offset Current 
Control on Loss of Magnetic Suspension Bearing [J]. Journal of aeronautical dynamics, 2011, 26(02): 404-408. (in Chinese)

[10] Z L WANG. Research on Electromagnetic Field Analysis and Eddy Current Power Consumption of Active Magnetic Suspension Bearing [D]. Jinan: Shandong University, 2009. (in Chinese)

[11] B QUAN, X Y YANG, Z G SHI, et al. Heating Model and Calculation Method of Active Magnetic Bearing Loss [C]. National Conference on Reactor Structural Mechanics, October, 16, Guilin, China, 2006: 200-204. (in Chinese)

[12] G Z FENG, S G YAO, F LIU, et al. Coupled numerical Analysis of Multiple Physical Fields inside Marine Generator [J]. Ship Science and Technology, 2008, 40(19): 109-113. (in Chinese)

[13] M Y LI, J M CHEN, Q HU. Thermal Performance Analysis of Cone Hydrostatic Bearing Based on Coupling Heat Transfer [J]. Mechanical Research and Application, 2014(3): 36-38. (in Chinese)

[14] D WEI, H T PANG, M DUAN, et al. Fluid-Solid Coupling Heat Transfer Analysis and Experimental Verification of Diesel Engine Cylinder Head [J]. Mechanical Design and Manufacturing, 2019, (12): 67-70. (in Chinese)

[15] J F XU. ANSYS Workbench 15.0 Learn All by Yourself [M]. Beijing: Electronic Industry Press, 2014. (in Chinese)

[16] C M ZHAO, P MA, C L GONG, et al. Research on Stress Field and Temperature Field of High Precision Hydrostatic Spindle based on Unidirectional Flow-solid Coupling [J]. Lubrication and Sealing, 2014, 39(5): 62-68. (in Chinese)

[17] L XIN. Theoretical Analysis and Experimental Verification of Temperature Field of Magnetic Suspension Bearing [D]. Wuhan: Wuhan University of Technology, 2011. (in Chinese)

[18] Y ZHANG. Study on Flow Field Characteristics of Particle Double-Phase Flow [D]. Taiyuan: North China University, 2018. (in Chinese)

[19] J S ZENG. Study on Flow Field and Discharge System in Dilution Area of High Concentration Bleaching Tower Based on CFD [D]. Shanghai: South China University of Technology, 2011. (in Chinese)

[20] C ZHANG, H R JU, D L ZHANG, et al. PIV Measurement and Numerical Investigation on Flow Characteristics of Simulated Fast Reactor Fuel Subassembly [J]. Nuclear Engineering and Technology, 2020, 52(5): 1 .

\section{Biographical notes}

Jian-Hua Zhao, born in 1983, is currently an associate professor at Mechanical Engineering College, Yanshan University, China. He received his bachelor degree in 2006, master degree in 2010, $\mathrm{PhD}$ degree in 2013 from Yanshan University, China. His research interests include simulation and analysis of hydrostatic bearing, Magnetic-Liquid Double Suspension Bearing System. Tel: +86-15933502864; E-mail: zhaojianhua@ysu.edu.cn.

Ji-Sheng ZHAO, born in 1995, is currently a postgraduate student of Yanshan University, China.

E-mail: 657183196@qq.com.

Sheng LI, born in 1995, is currently a postgraduate student of Yanshan University, China.

E-mail: 13394466235@163.com.

Zhe WANG, born in 1994, is currently a postgraduate student of Yanshan University, China.

E-mail: 1114048872@qq.com.

Guo-Jun DU, born in 1961, is currently a professor at Yanshan University, China. He received his bachelor degree in 1983 from
Northeast Heavy Machinery Institute, China. He received his master degree in 1991, PhD degree in 2004 from Yanshan University, China. His research interests include nonlinear vibration of complicated shell structure.

Tel: +86-18633515962; E-mail: dugj2002@ysu.edu.cn.

Dian-Rong GAO, born in 1962, is currently a professor and a $\mathrm{PhD}$ candidate supervisor at Mechanical Engineering College, Yanshan University, China. He received his bachelor degree in 1984, master degree in 2010 from Northeast Heavy Machinery Institute, China.He received his $\mathrm{PhD}$ degree in 2001 from Yanshan University, China. His research interests include fluid power transmission and control.

E-mail: gaodr@ysu.edu.cn. 
Figures

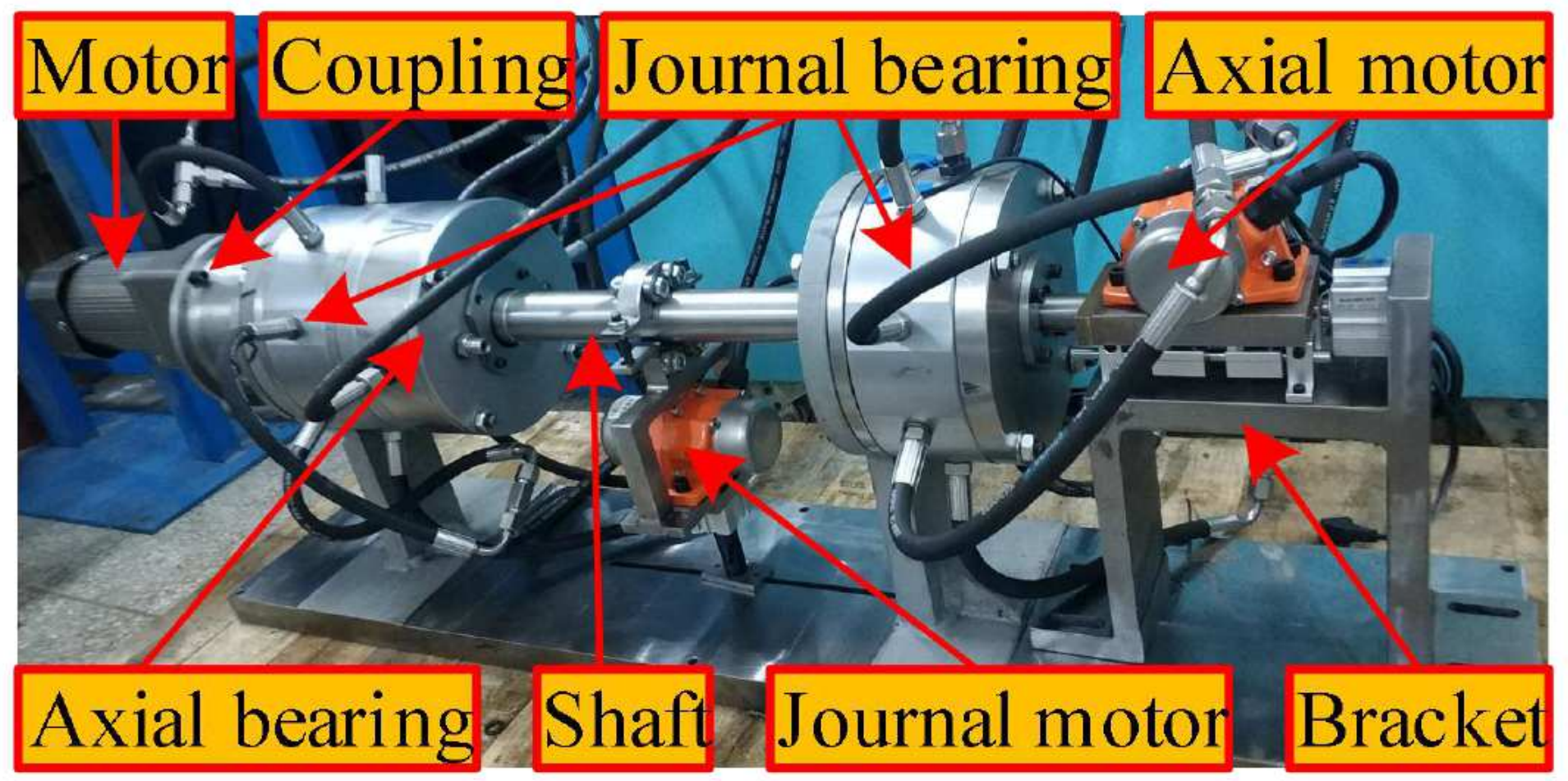

Figure 1

Magnetic Liquid Double Suspension Bearing

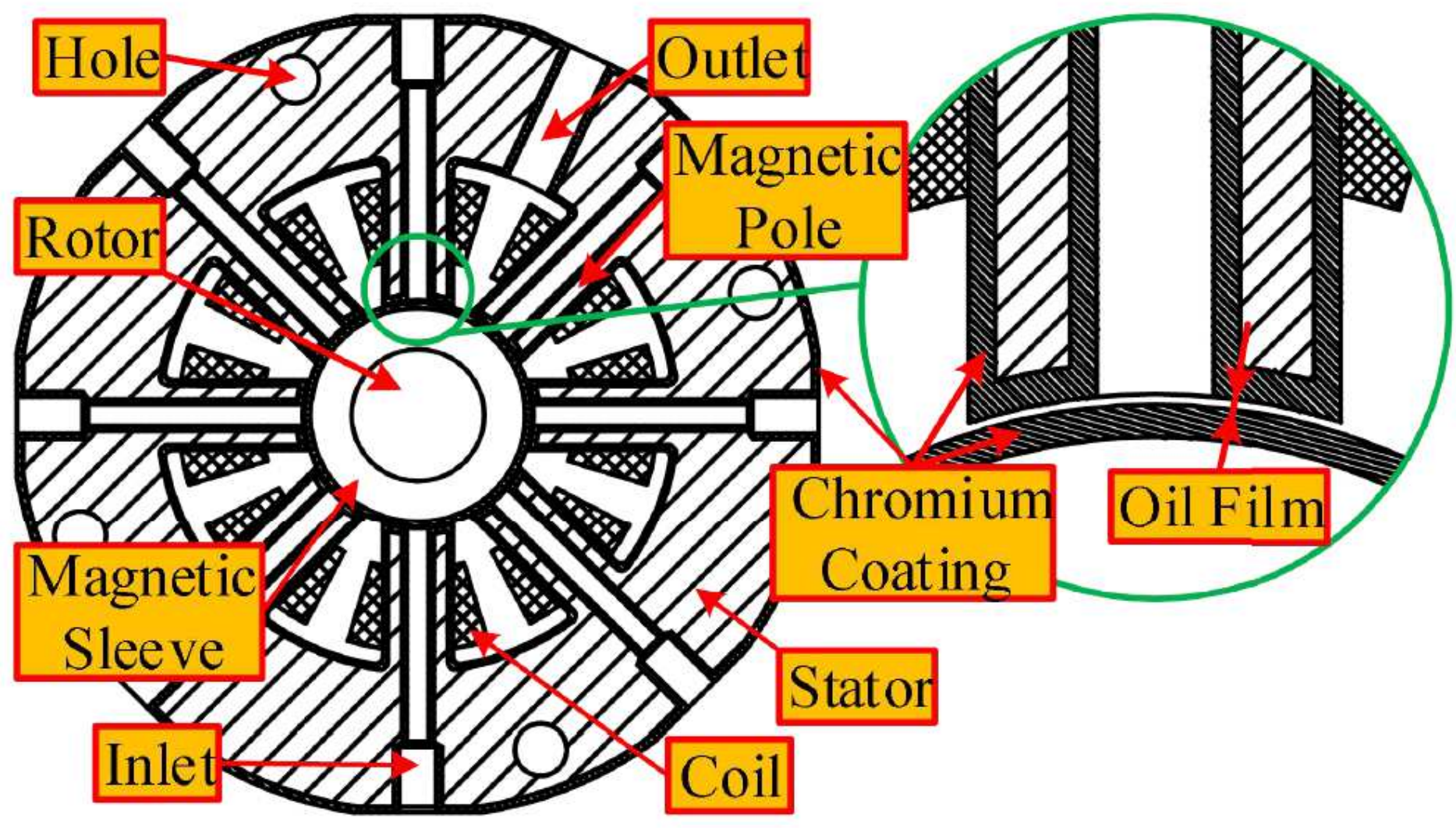


Figure 2

Sectional view of radial unit of MLDSB

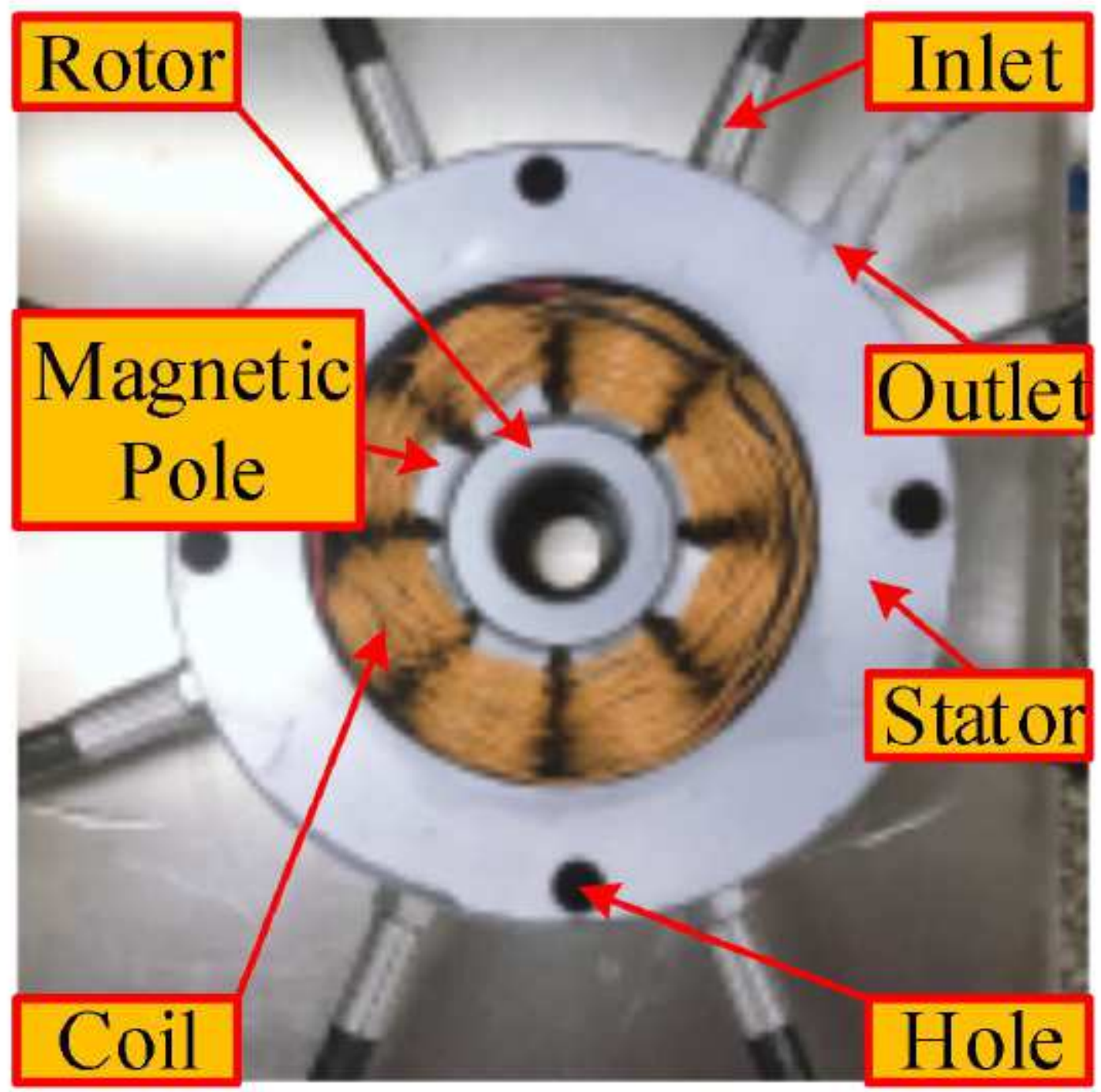

Figure 3

Photo of radial unit of MLDSB

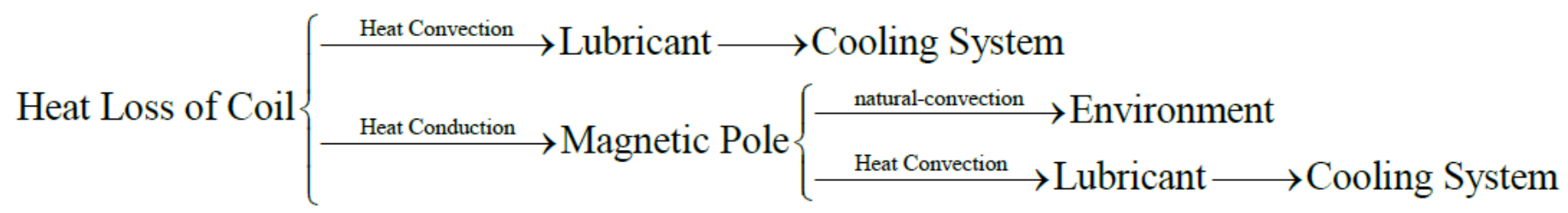

Figure 4

Heat dissipation pathways of MLDSB 


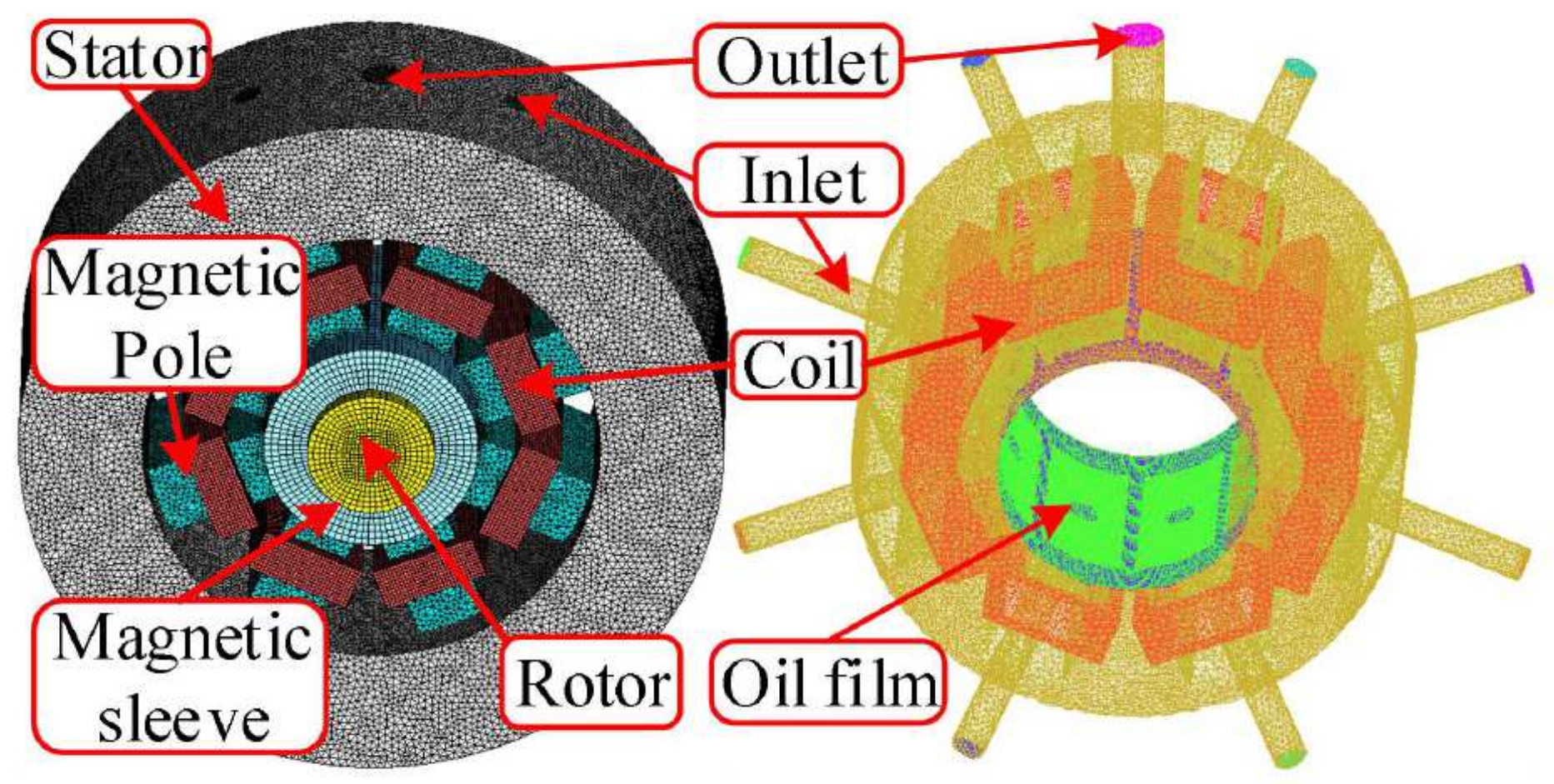

Figure 5

Grid of calculation domain of MLDSB (a)Solid state grid (b)Fluid state grid 


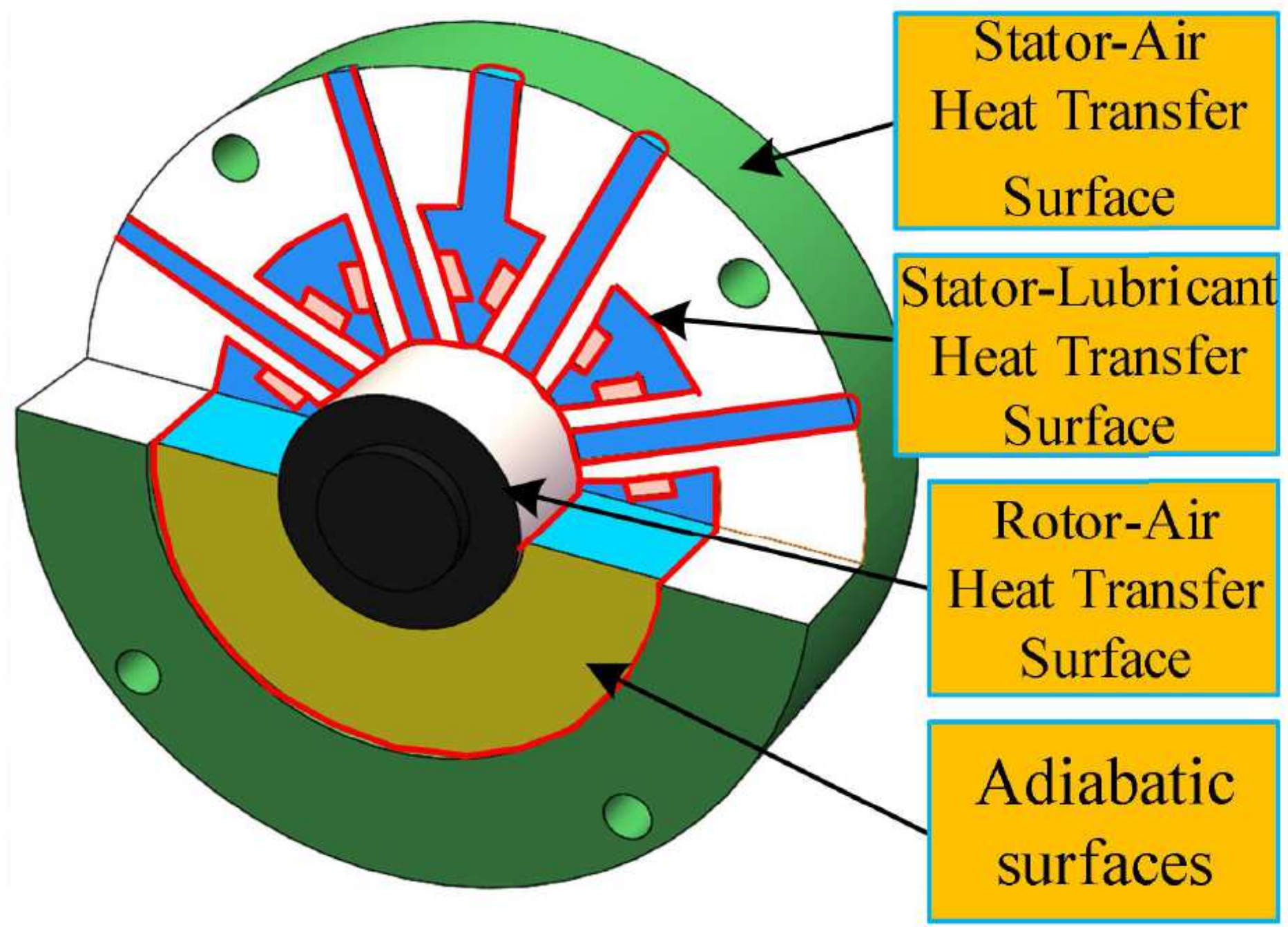

Figure 6

Heat transfer surface of MLDSB 


\section{Temperation $/{ }^{\circ} \mathrm{C}$}

\section{Outlet}

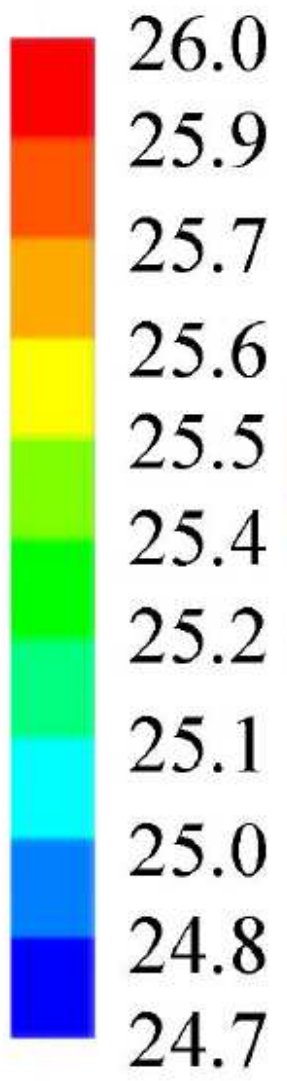

Figure 7

Cloud chart of temperature of MLDSB 


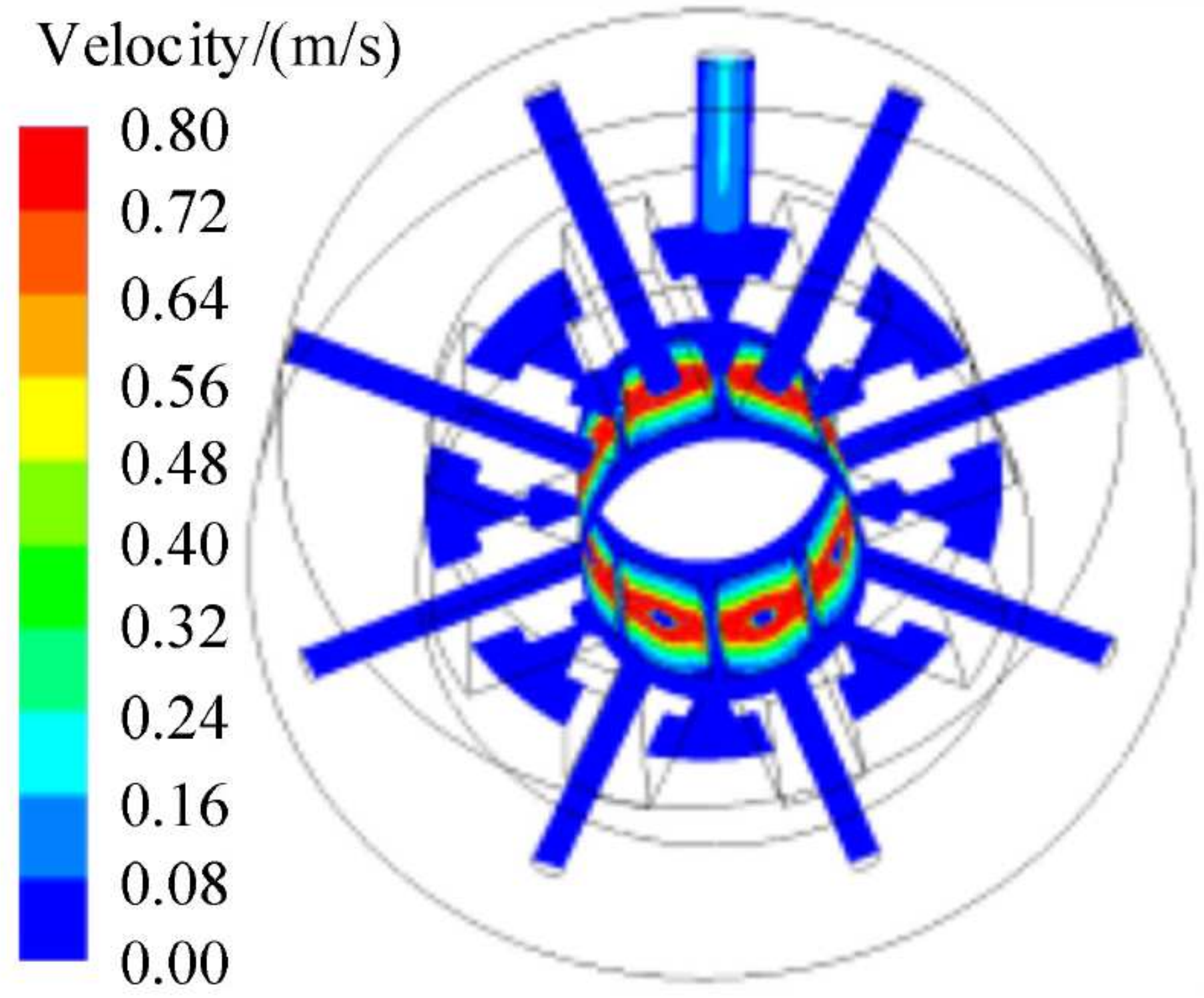

Figure 8

Cloud chart of velocity of MLDSB 


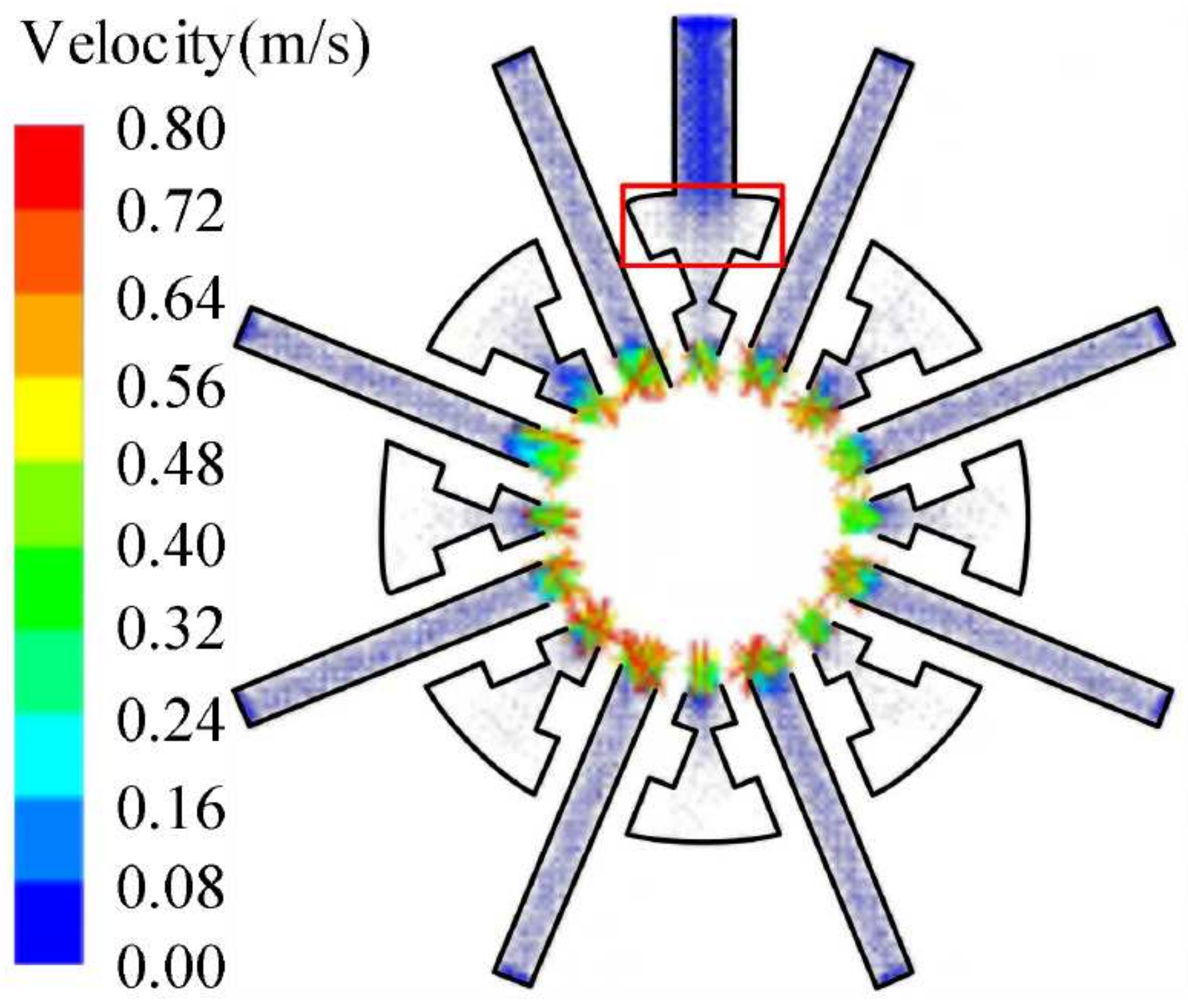

Figure 9

Flow vector-chart of MLDSB 


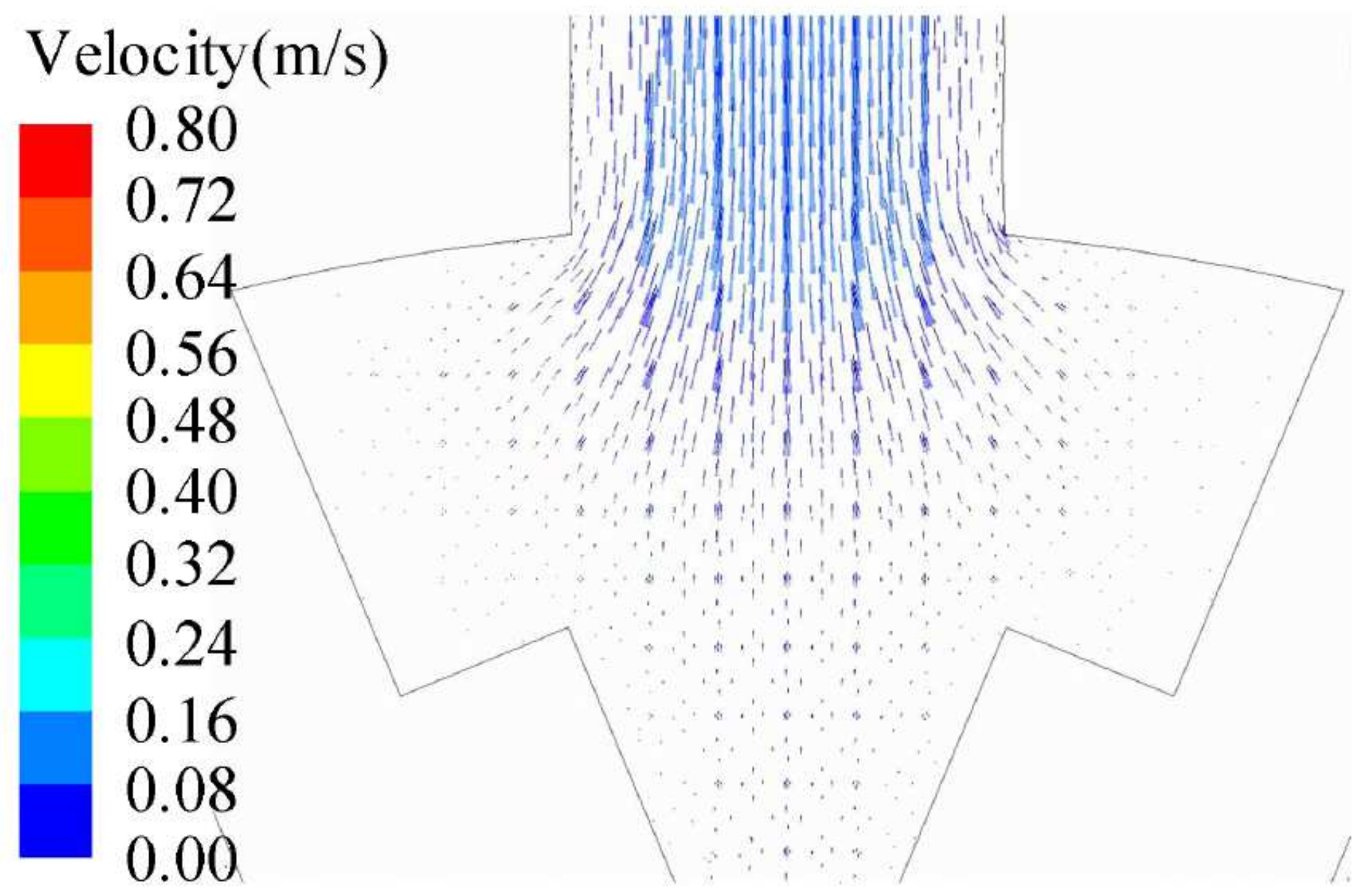

Figure 10

Partial flow vector-chart of MLDSB 


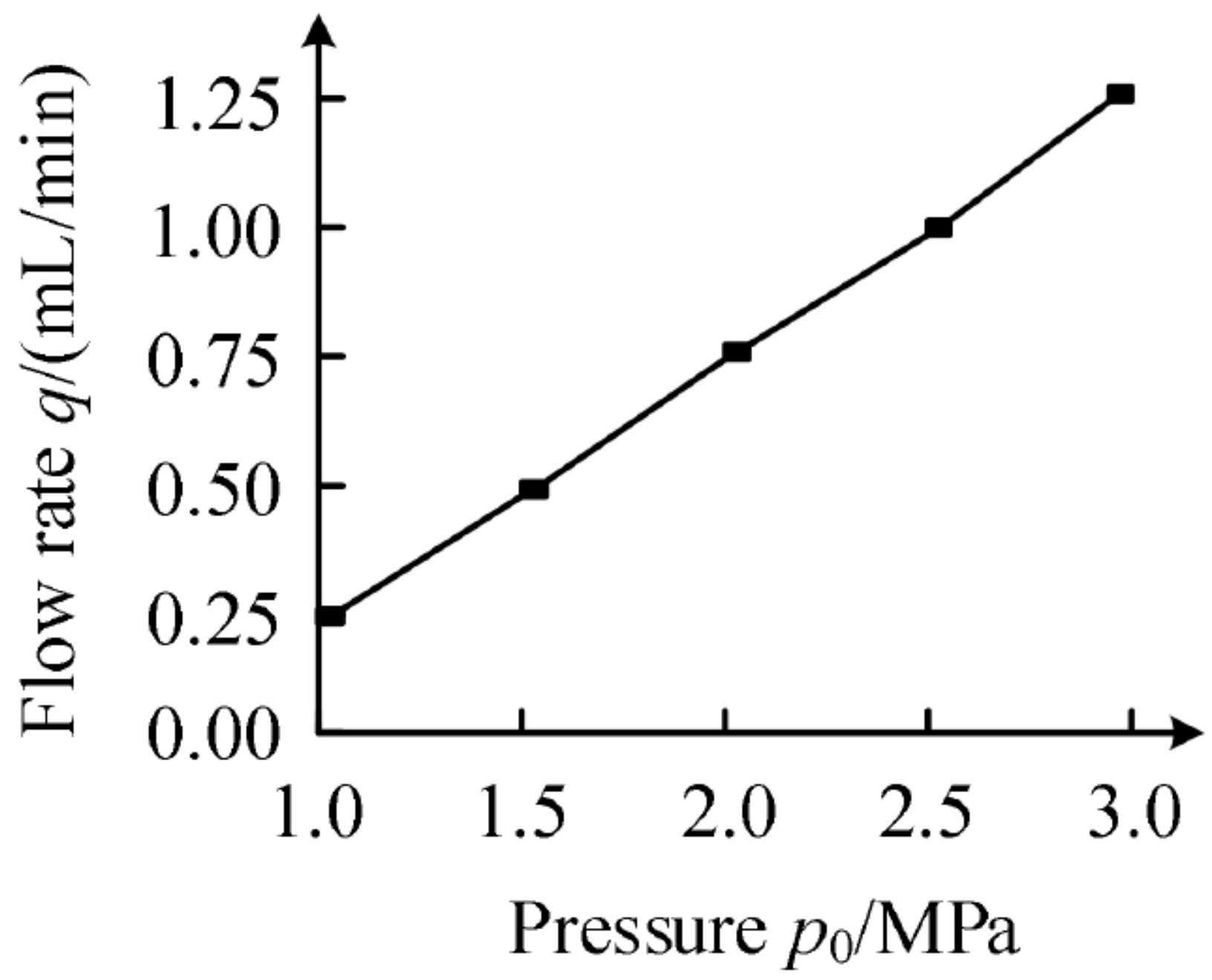

Figure 11

Curse between pressure and flow rate

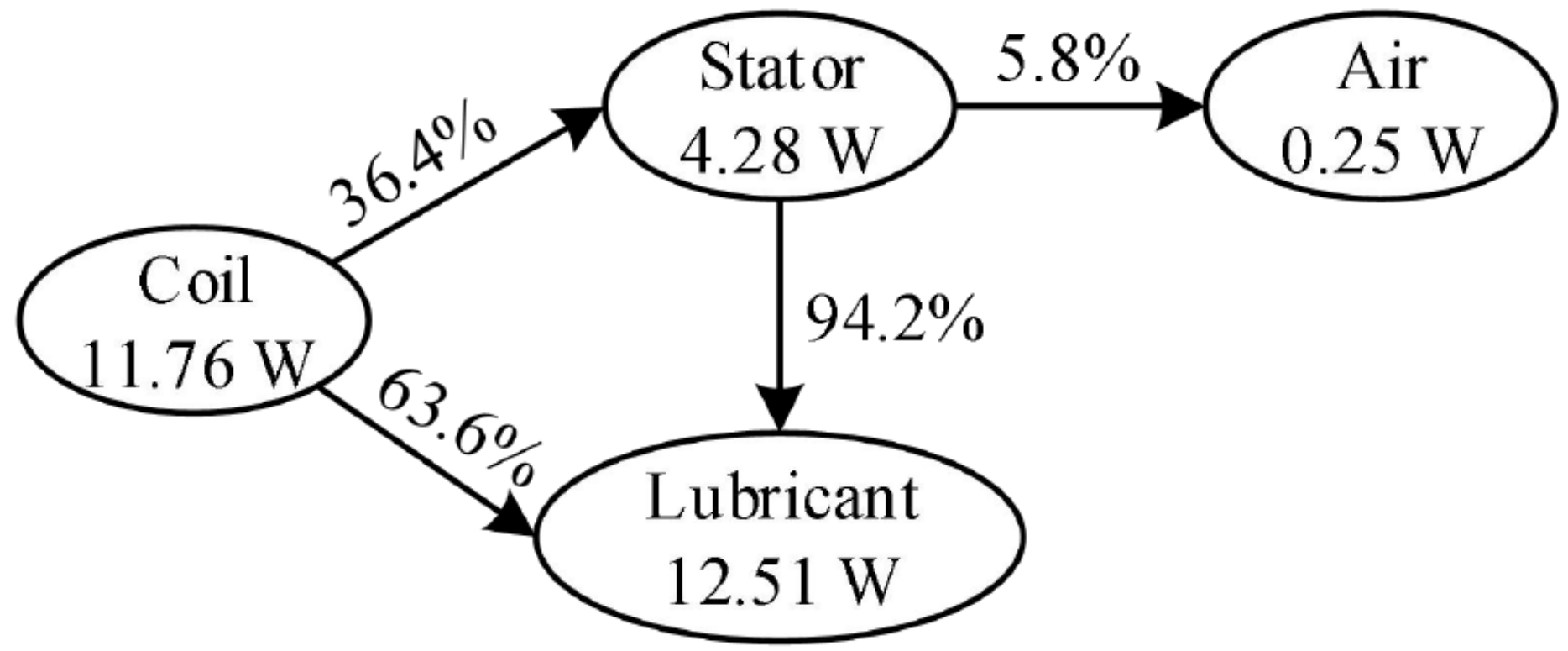


Figure 12

Heat transfer rate and ratio between surfaces

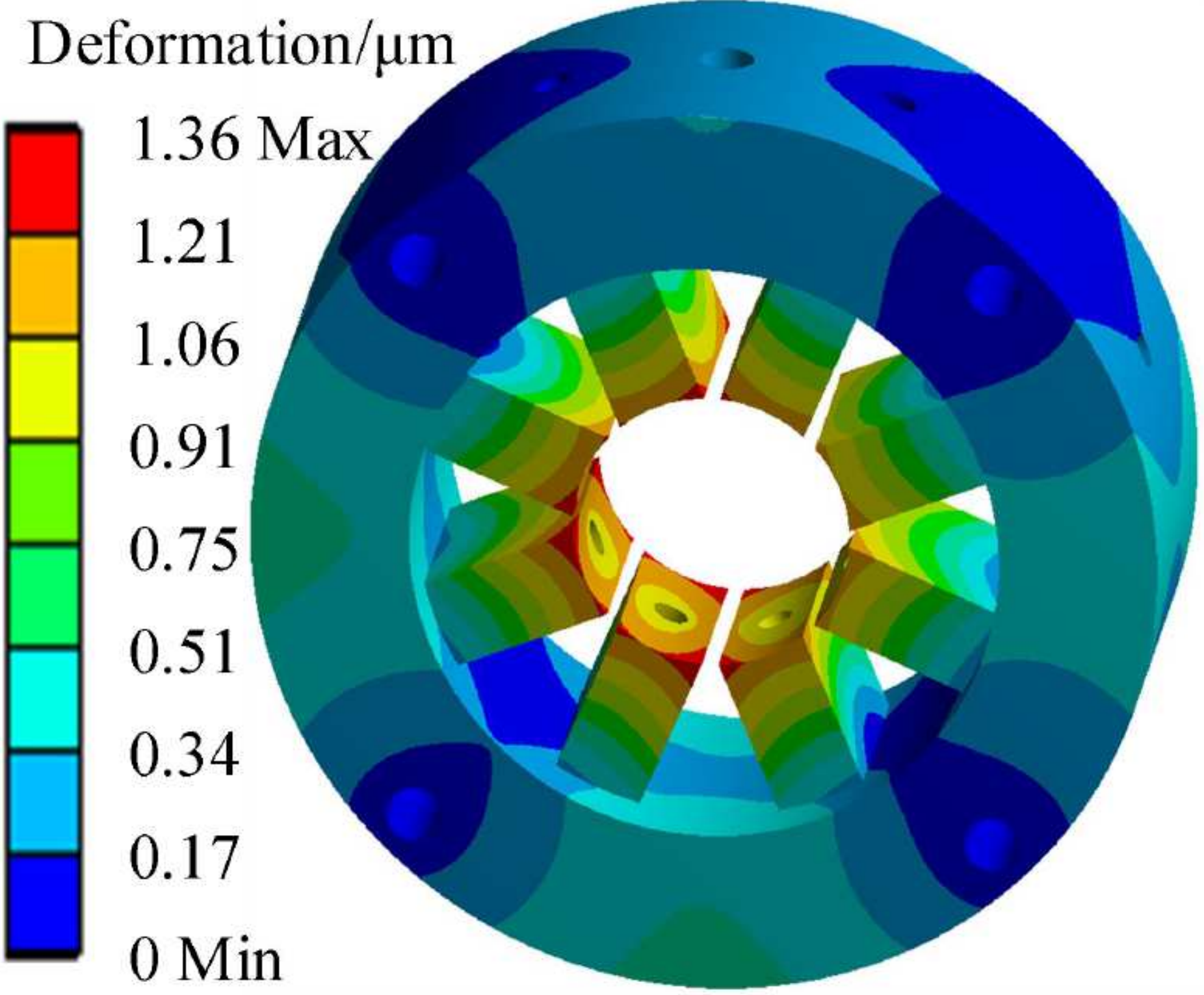

Figure 13

Cloud chart of thermal deformation of stator 


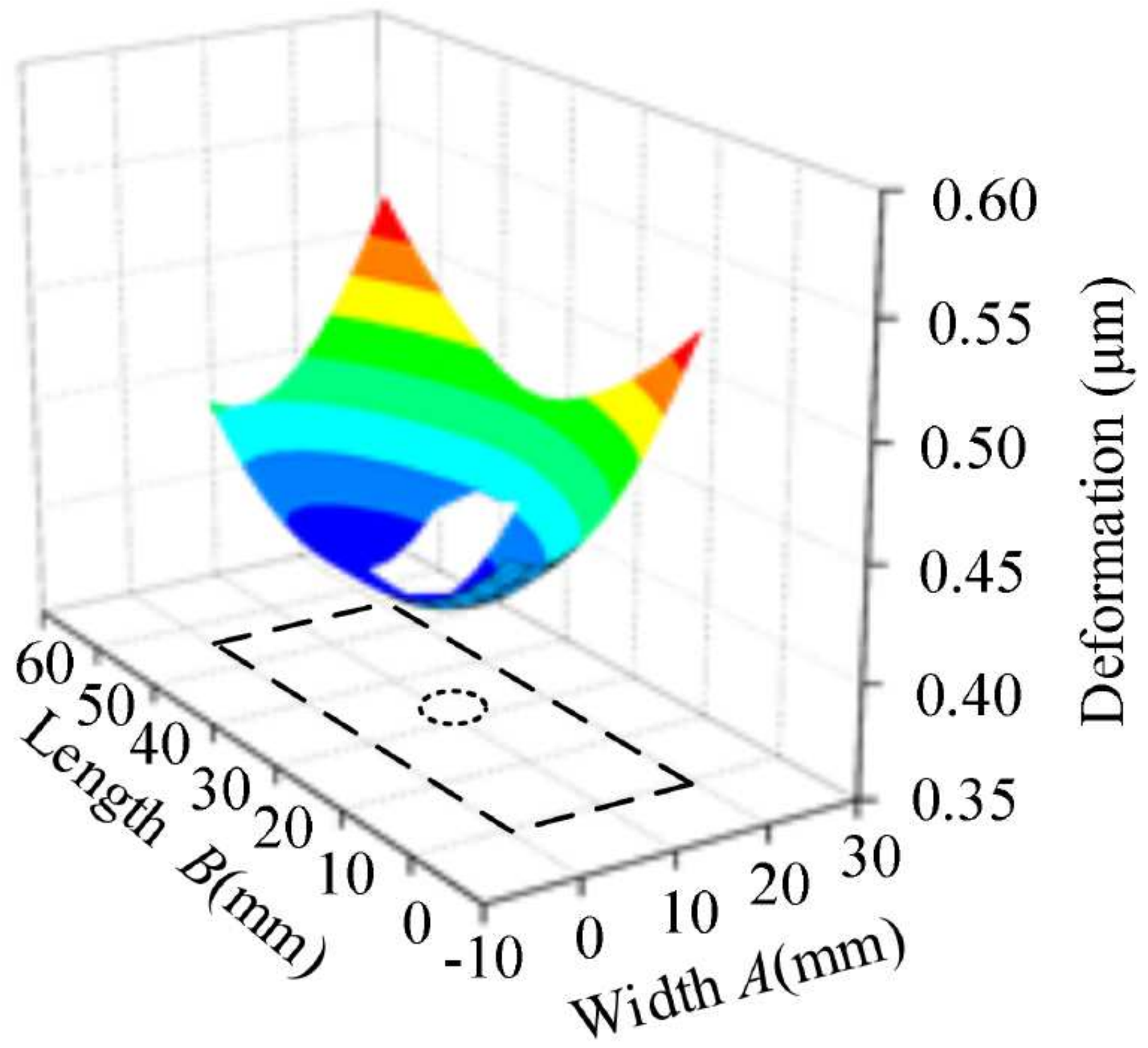

Figure 14

Peak diagram of thermal deformation of magnetic pole 


\section{Stress/MPa}

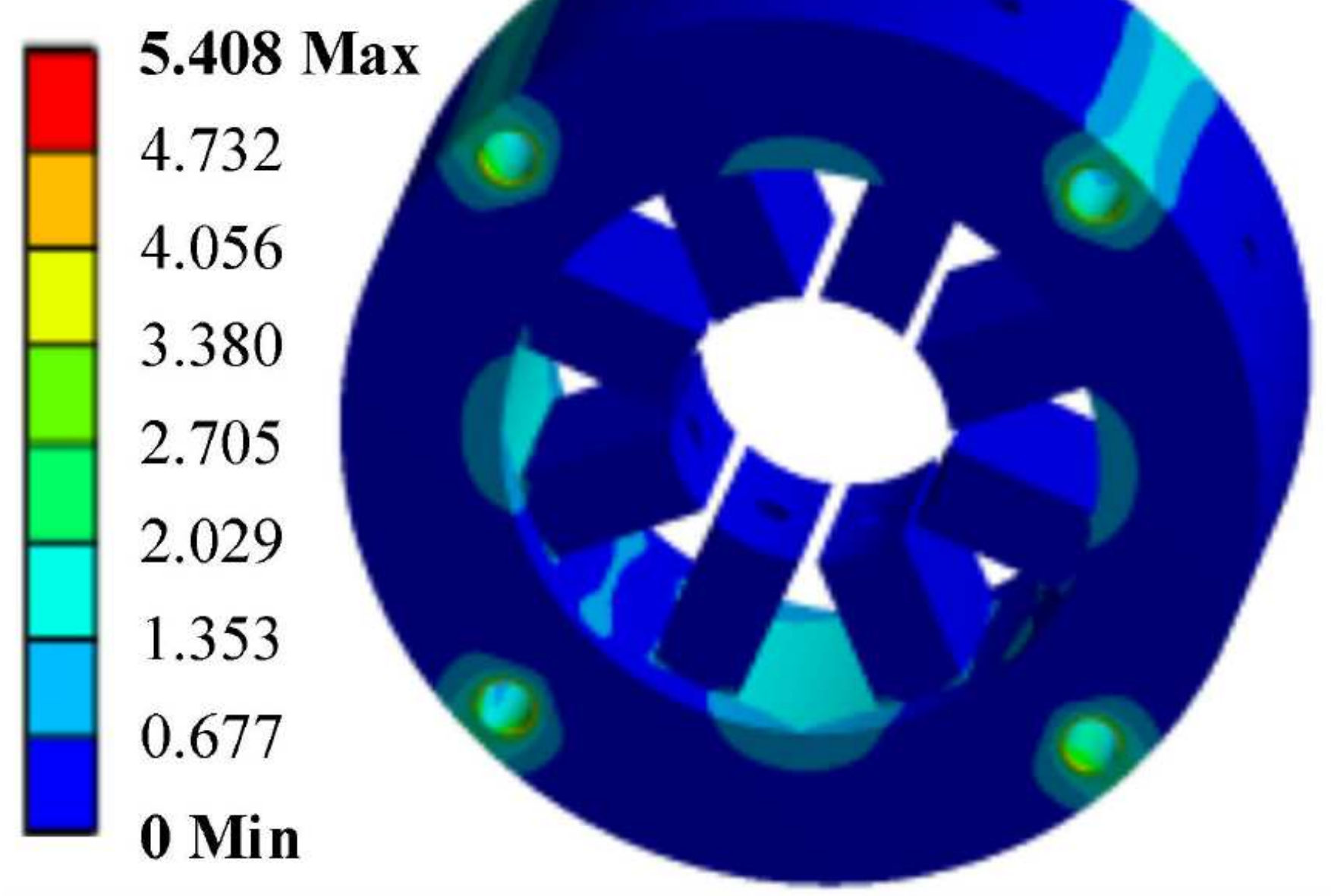

Figure 15

Cloud chart of stress of stator 


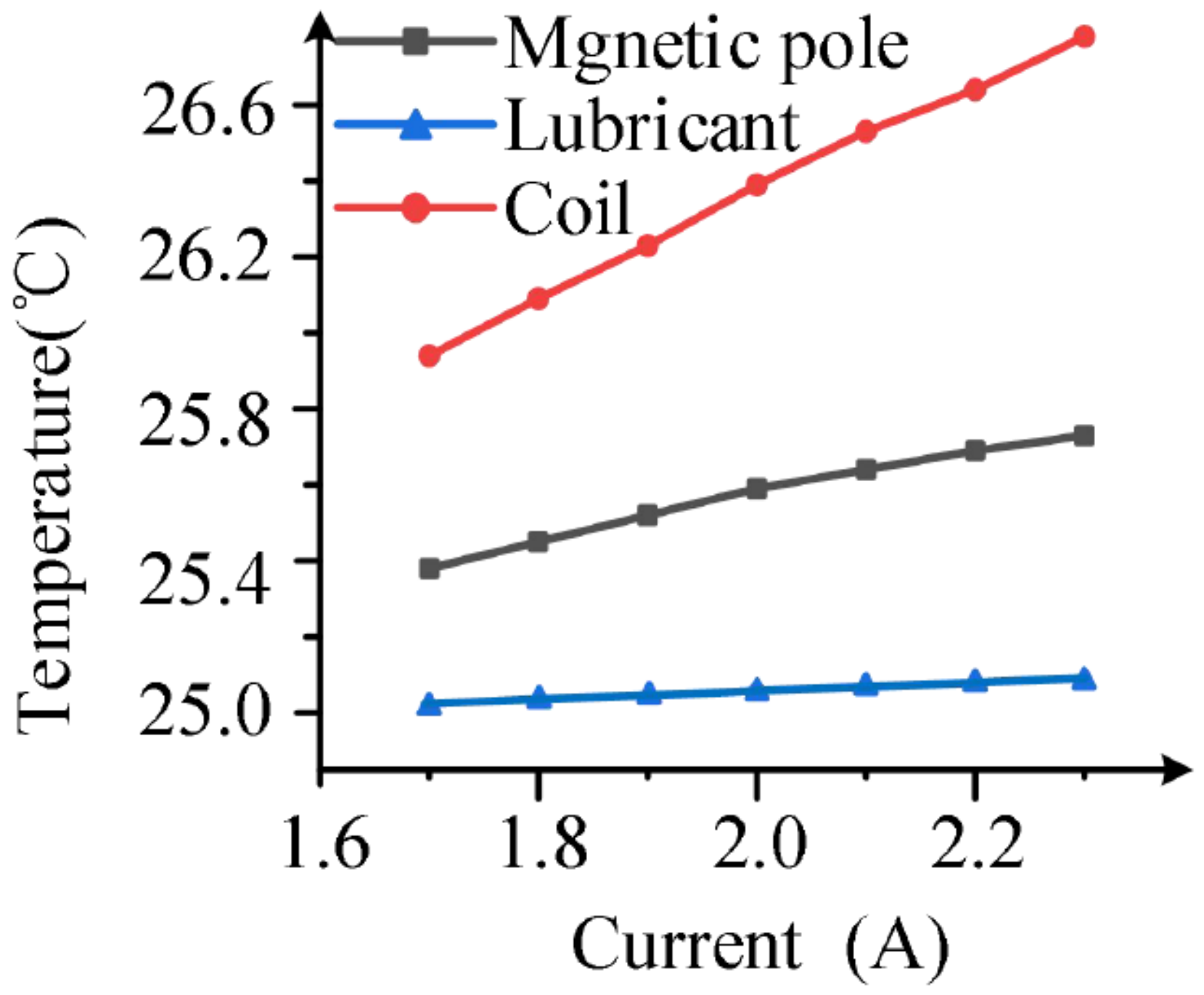

Figure 16

Curves between current and temperature of MLDSB 


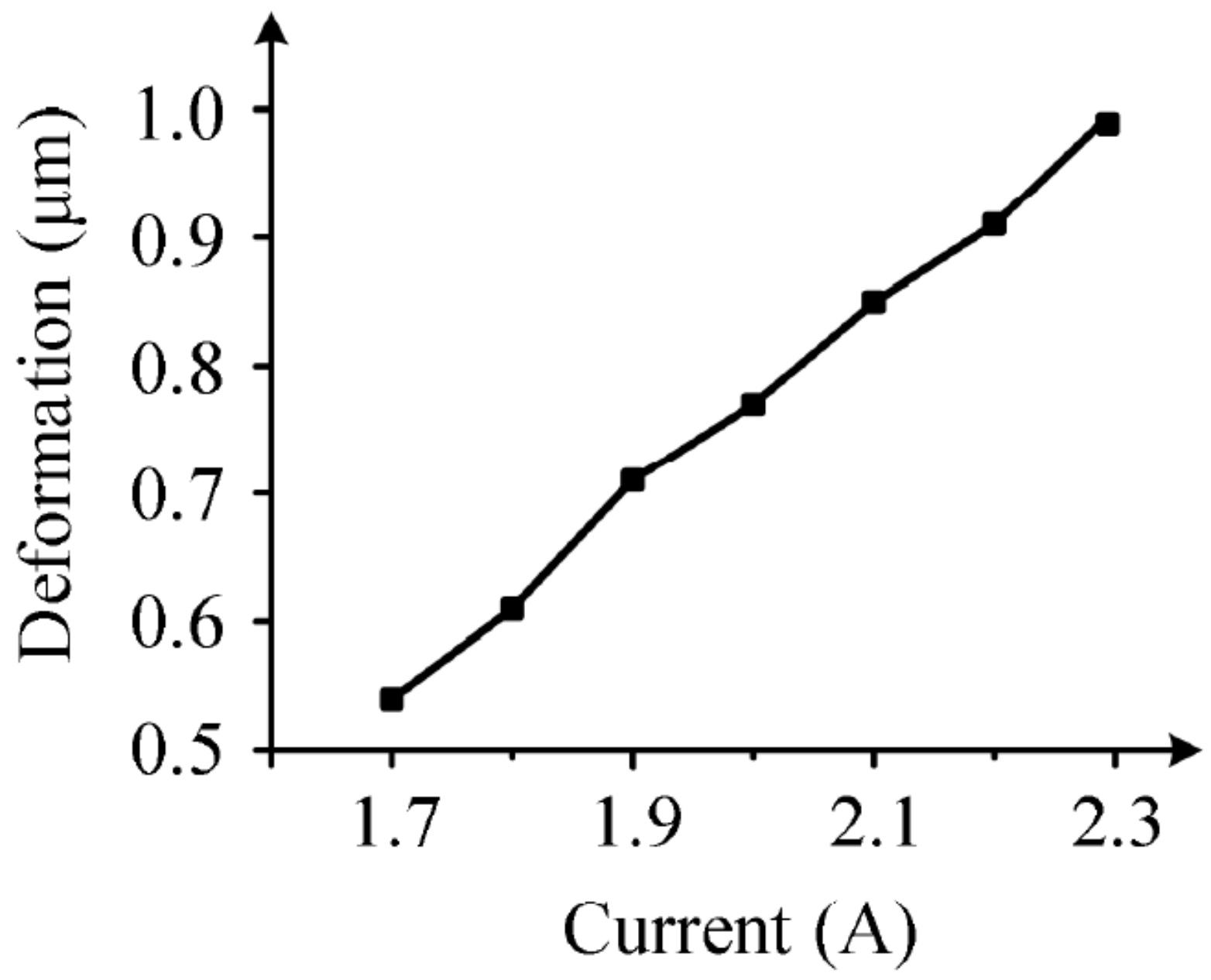

Figure 17

Curves between current and deformation of MLDSB 


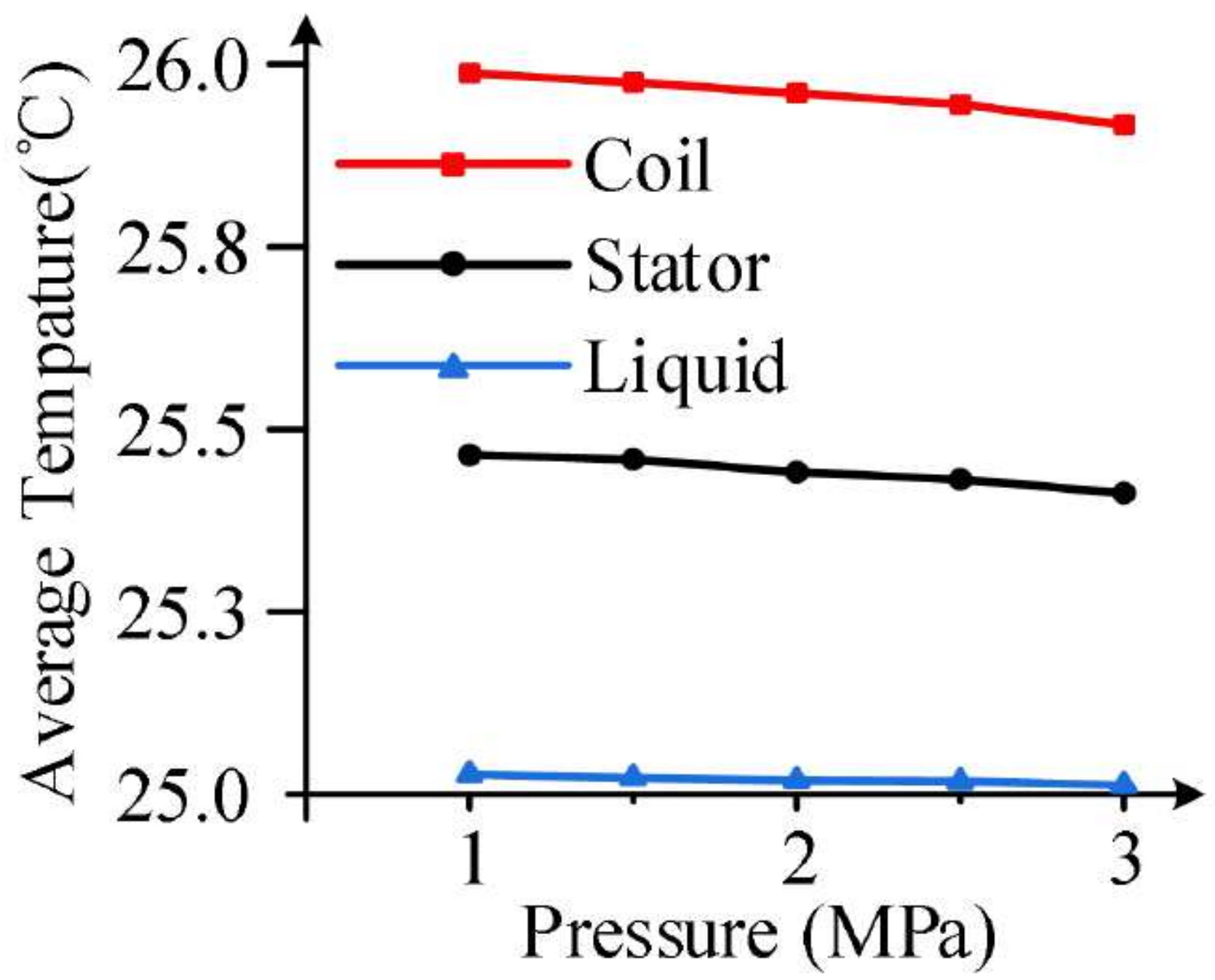

Figure 18

Curves between pressure and temperature of MLDSB 


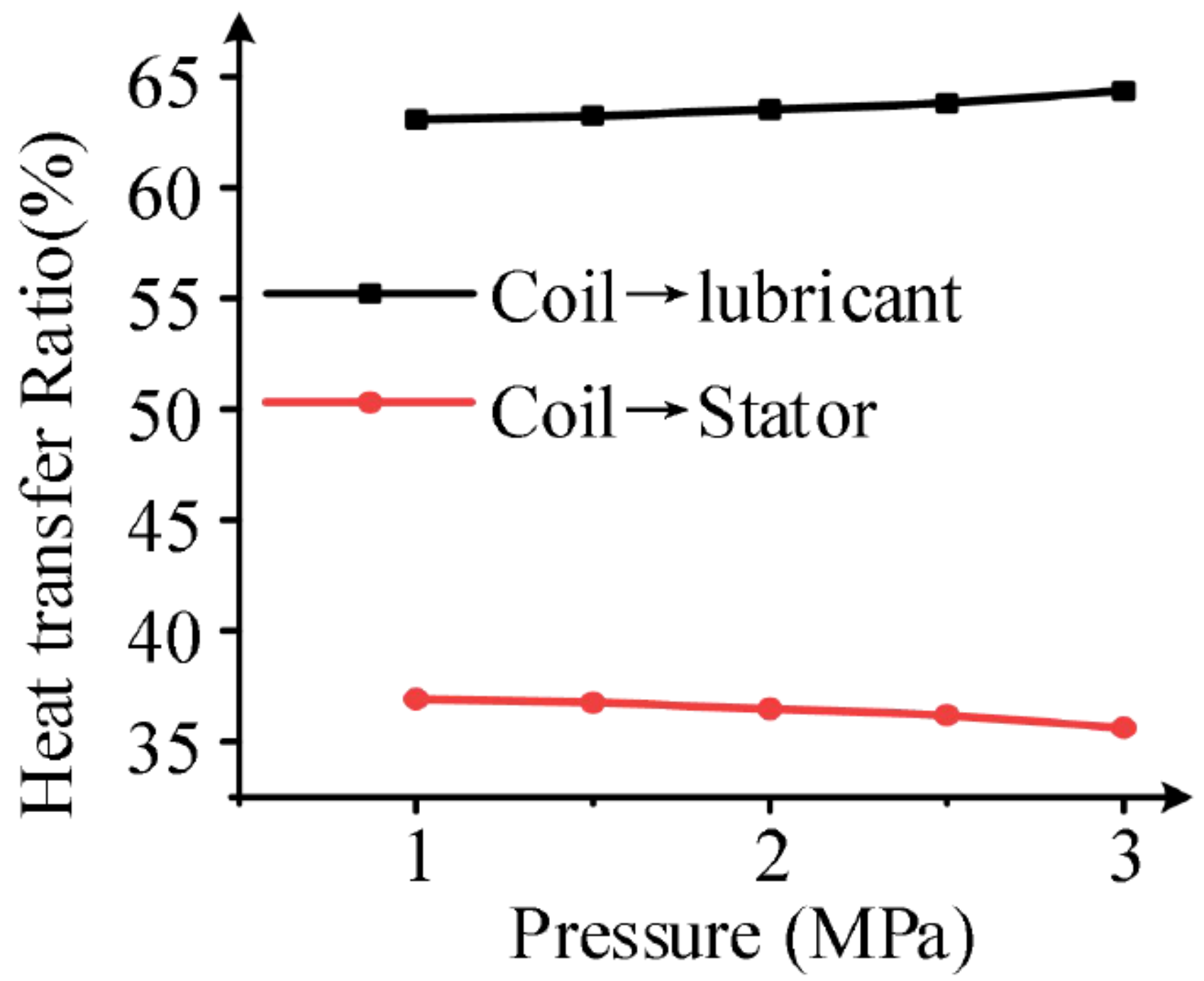

Figure 19

Effect of pressure on heat distribution law 


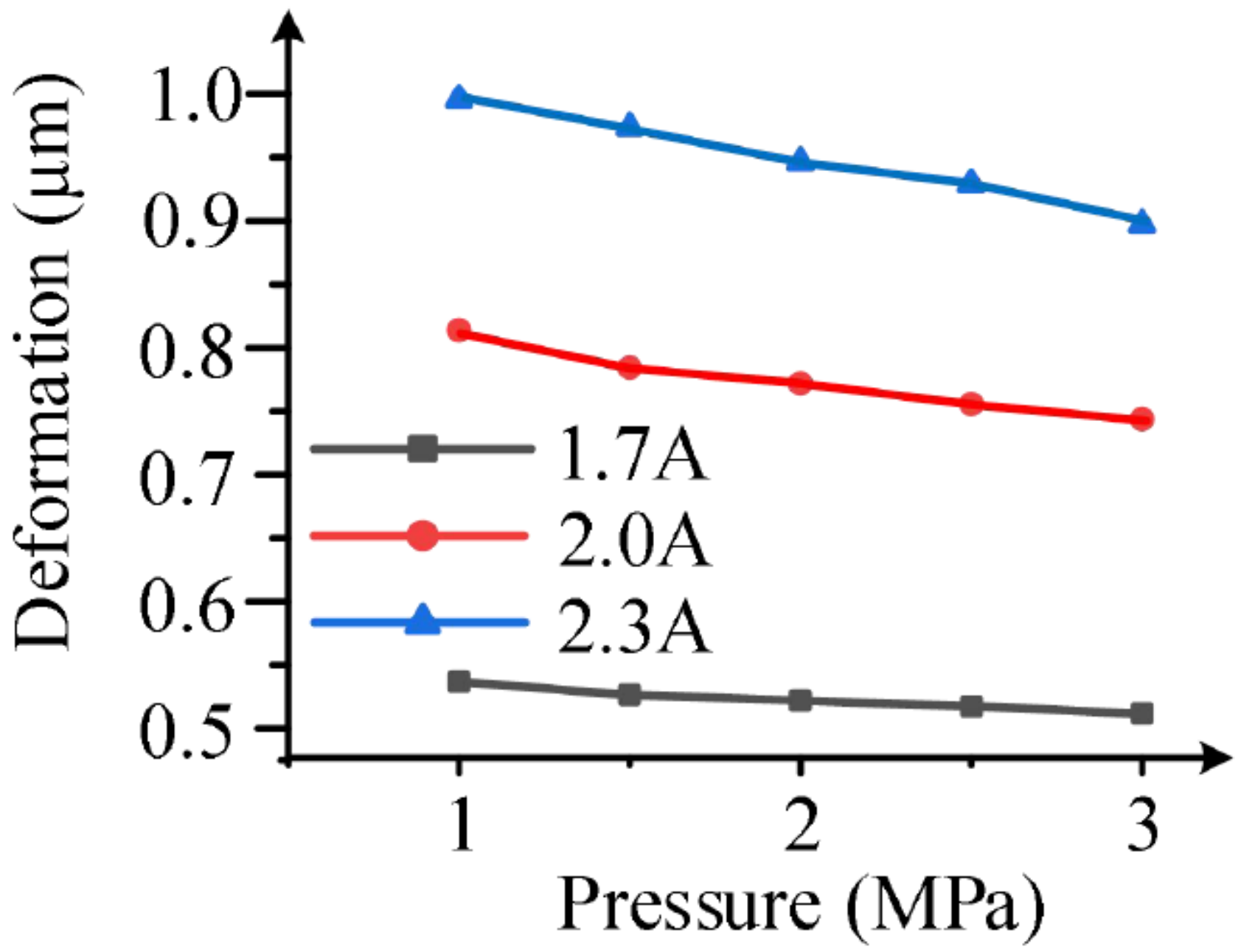

Figure 20

Curves between pressure and thermal deformation 


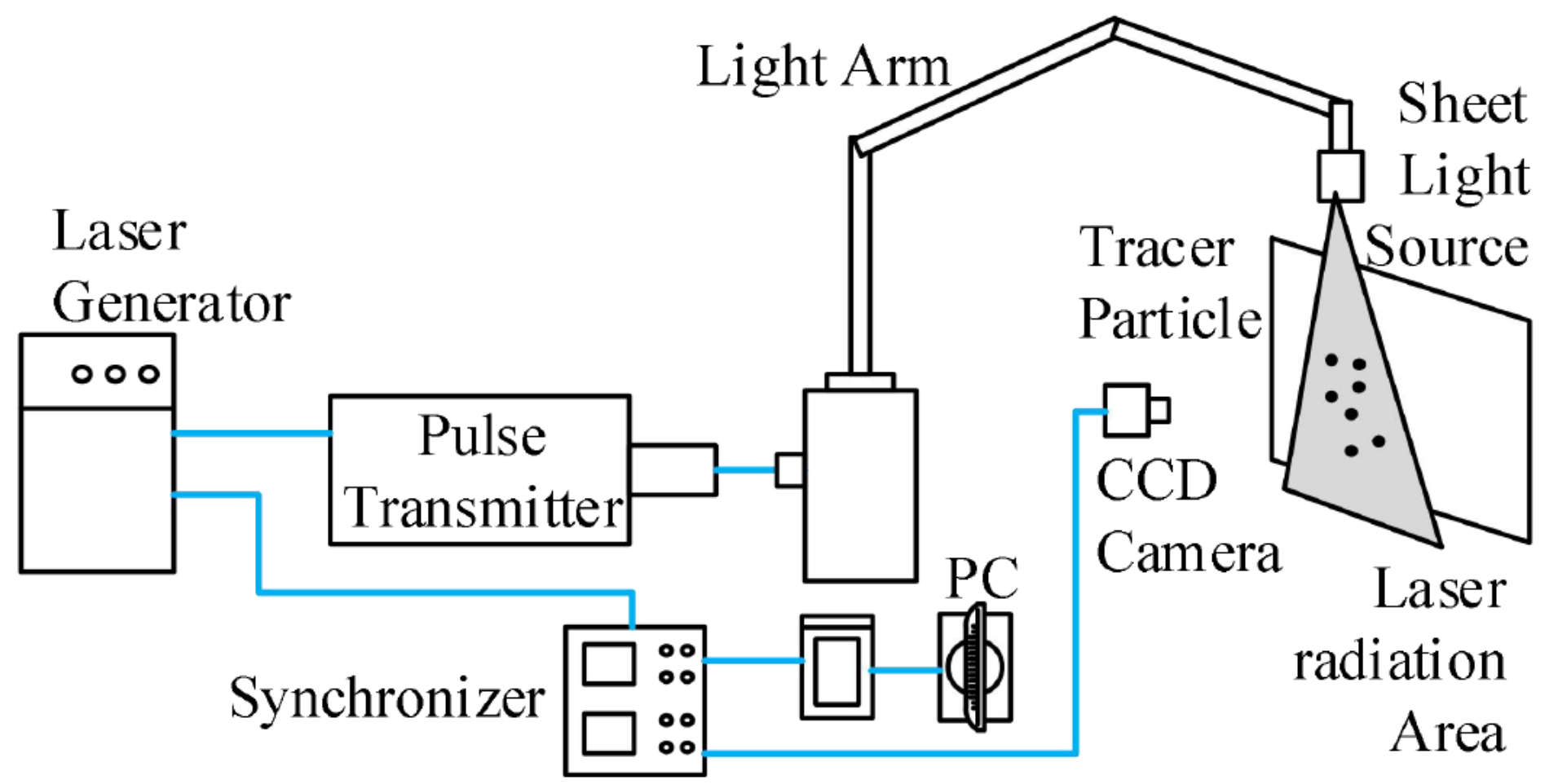

Figure 21

Composition and principle of PIV measure system 


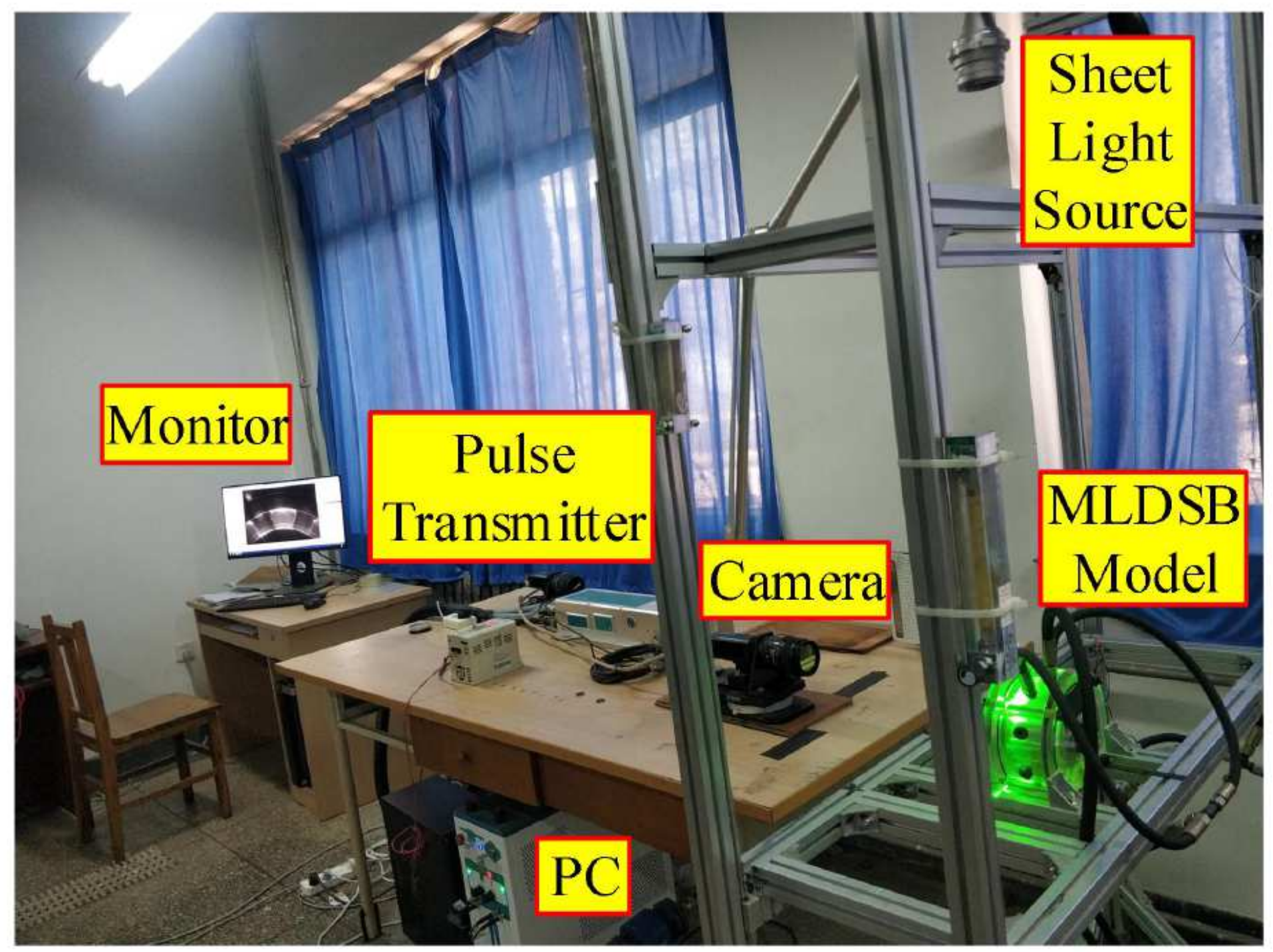

Figure 22

Photo of PIV measure system 


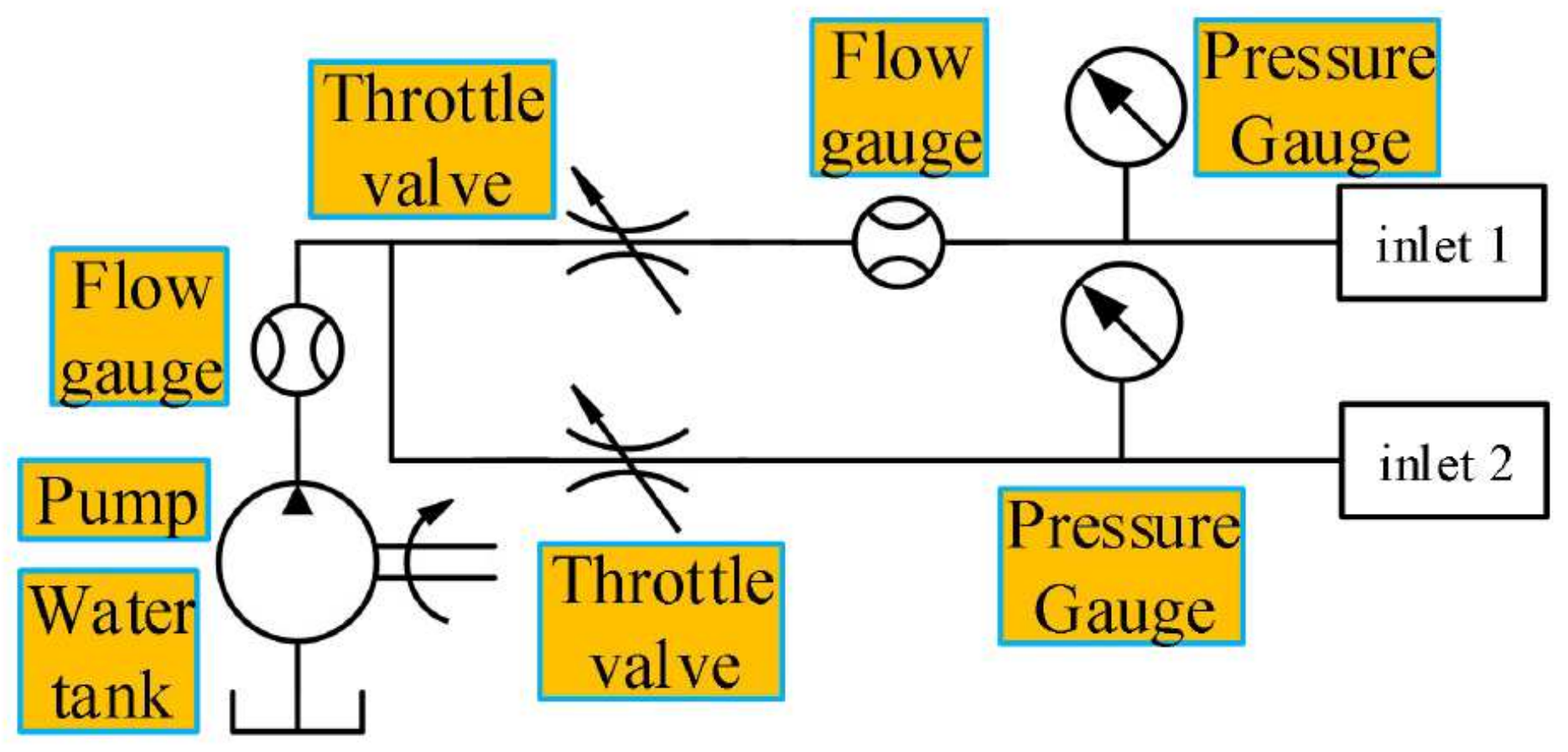

Figure 23

Lubricant supply system of MLDSB 


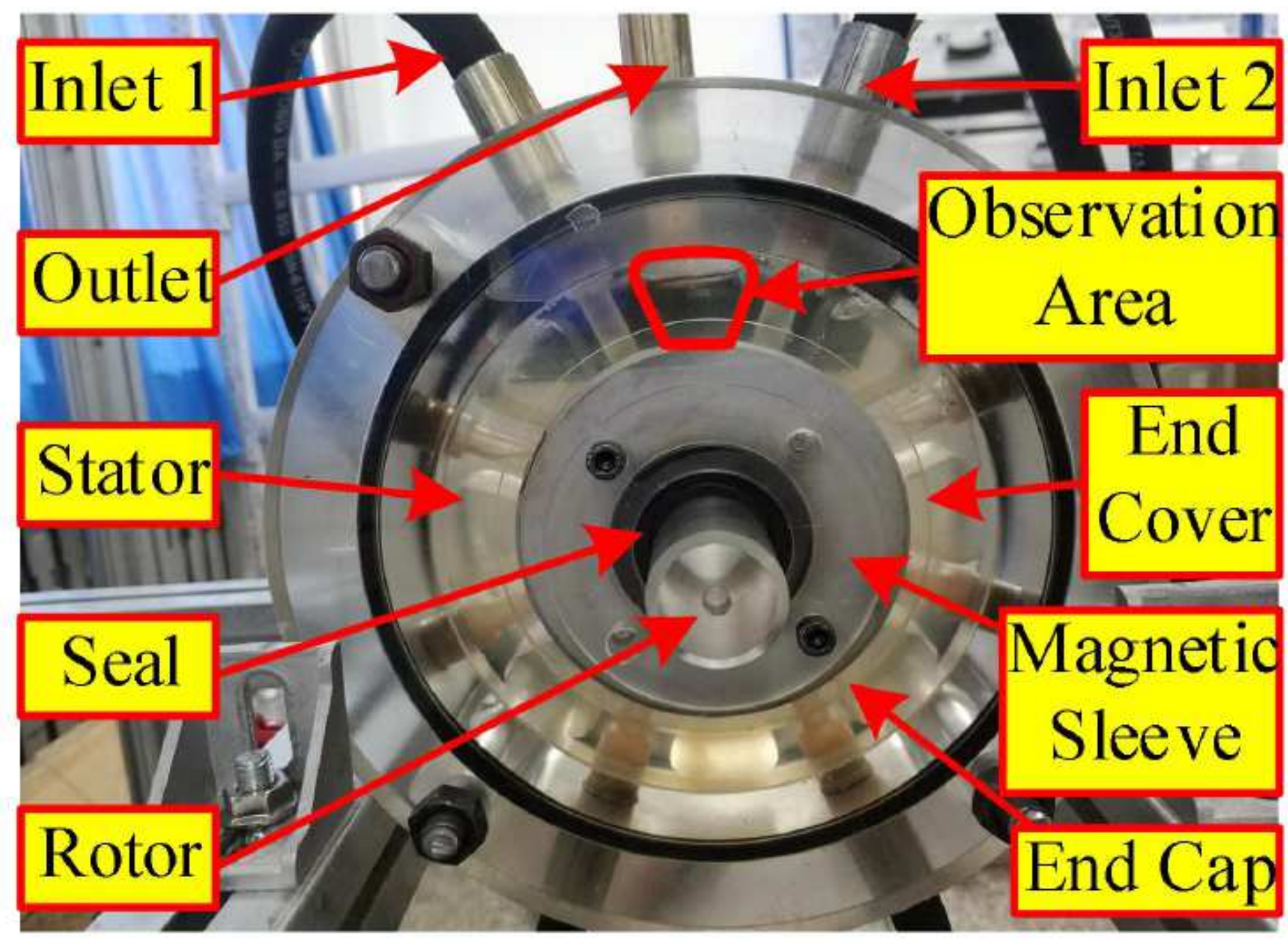

Figure 24

Model of journal bearing unit of MLDSB 


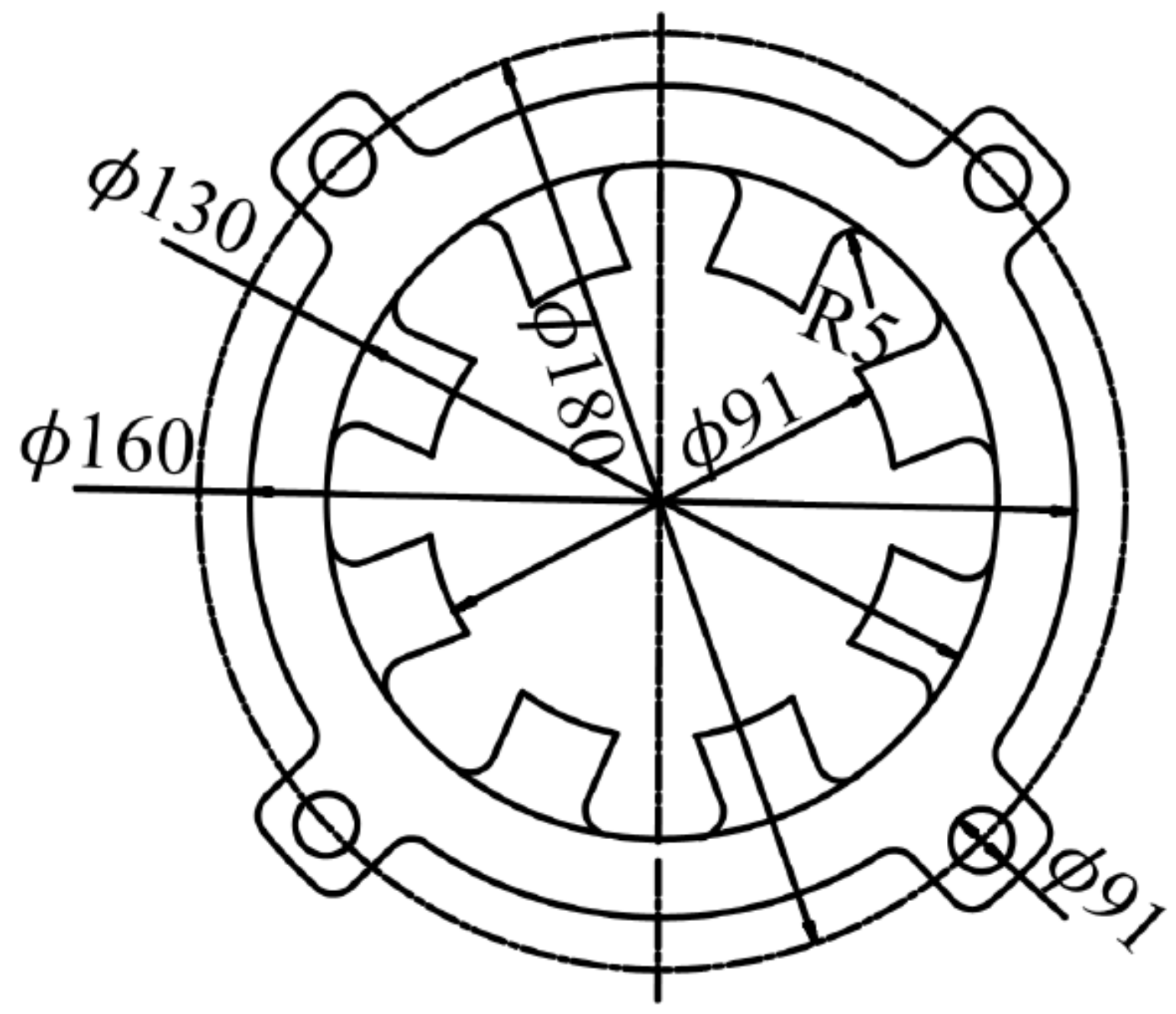

Figure 25

Stator model of MLDSB 


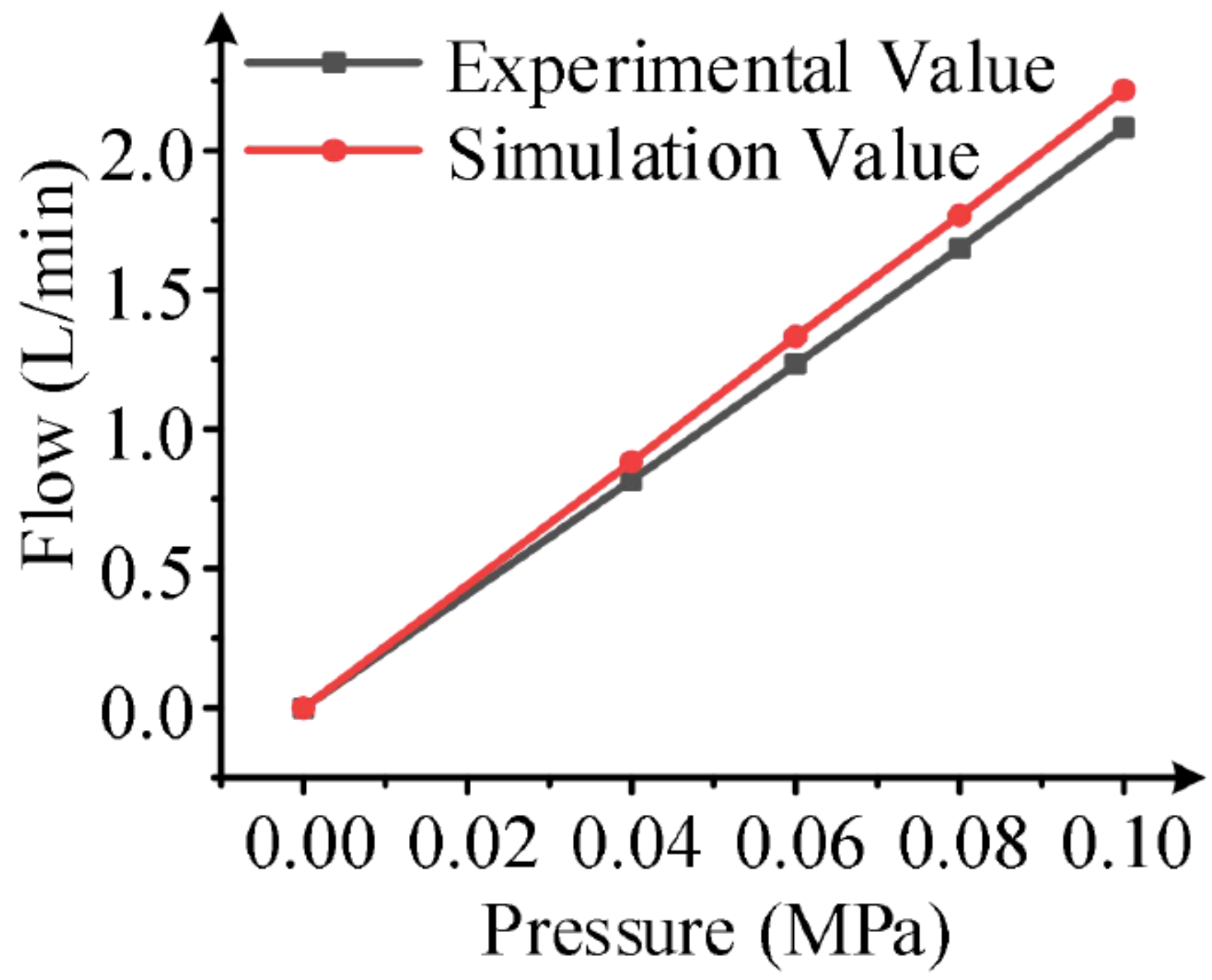

Figure 26

Simulation and experimental result of flow rate 


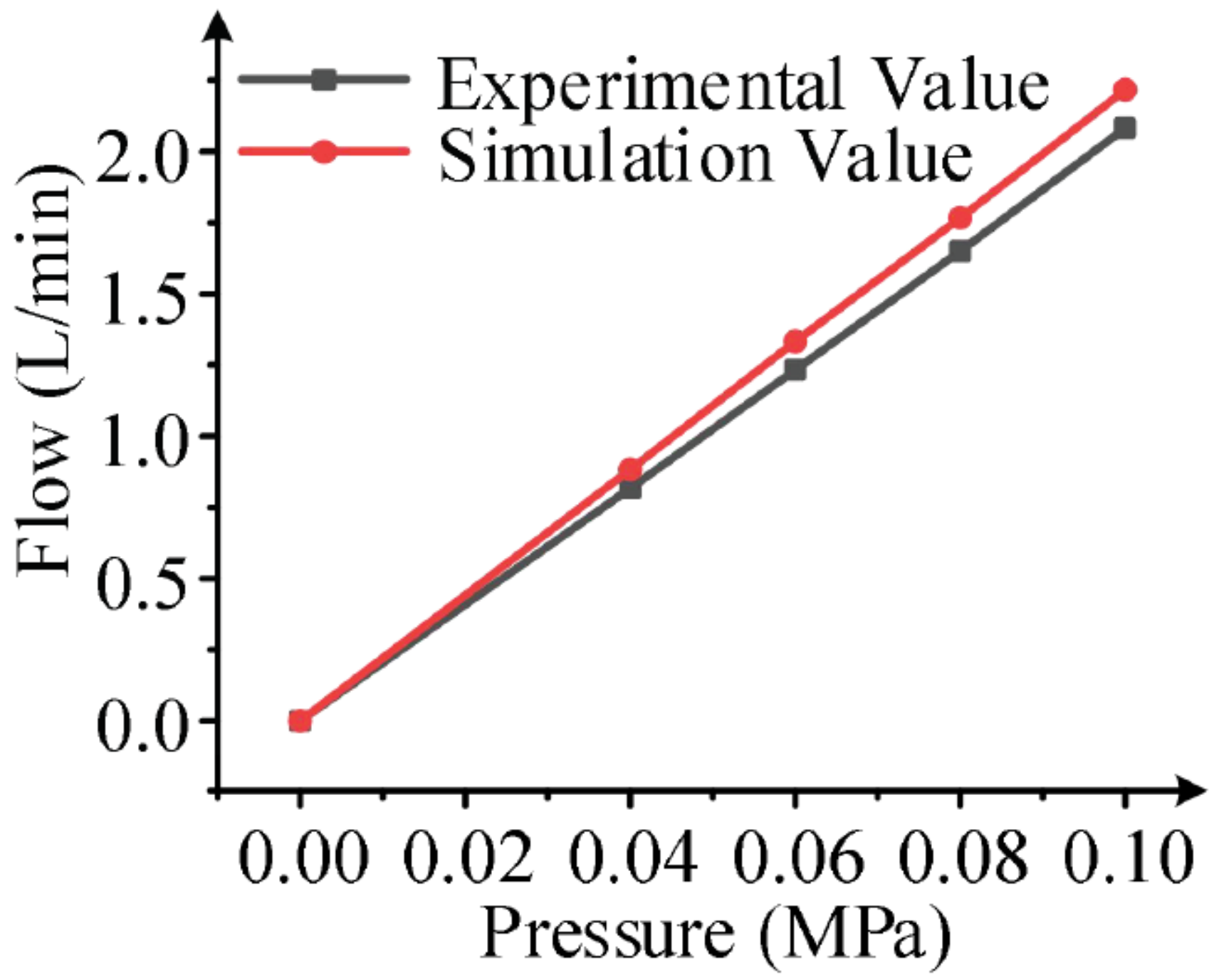

Figure 27

Simulation and experimental result of flow rate 


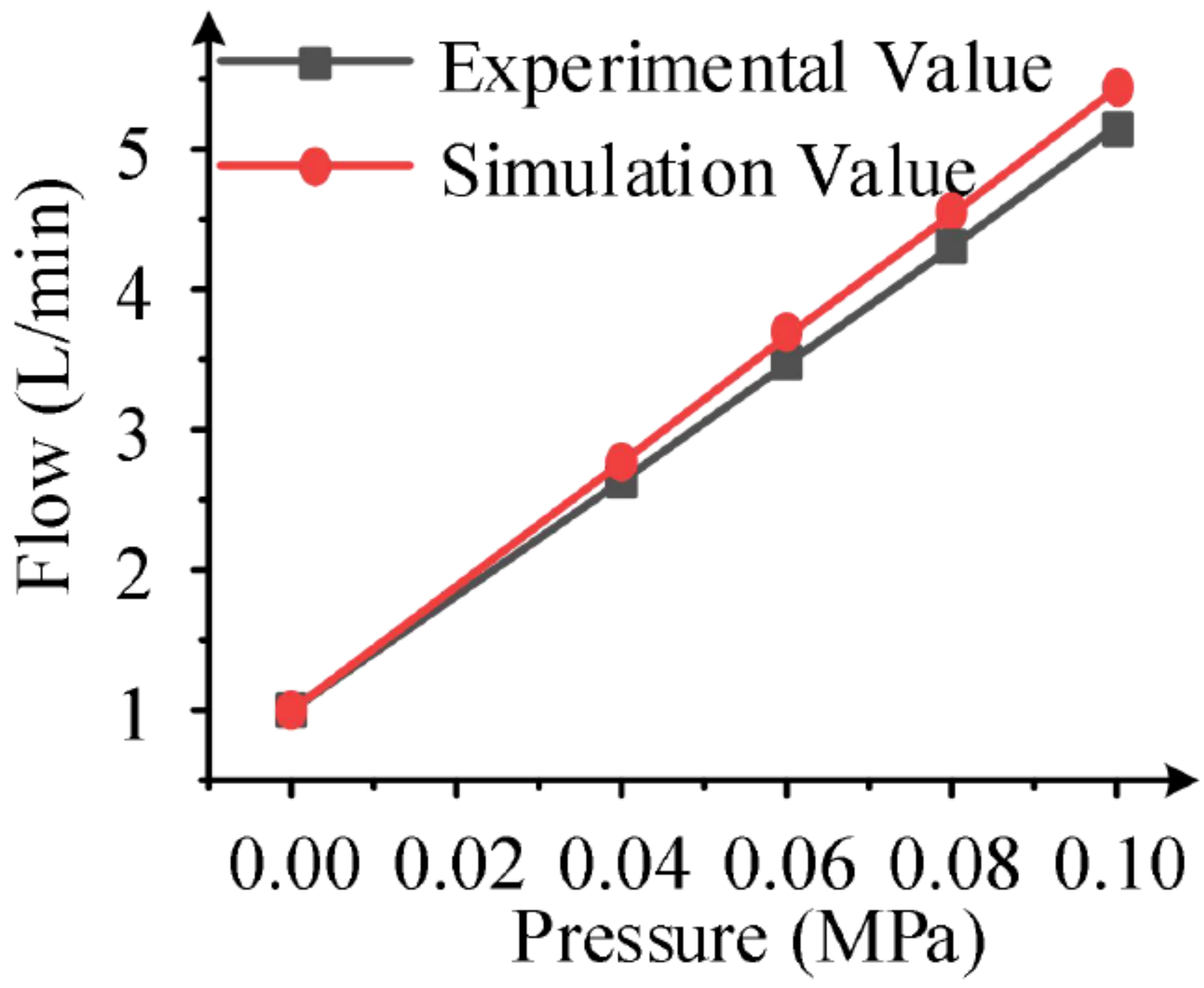

Figure 28

Simulation and experimental result of total flow rate 


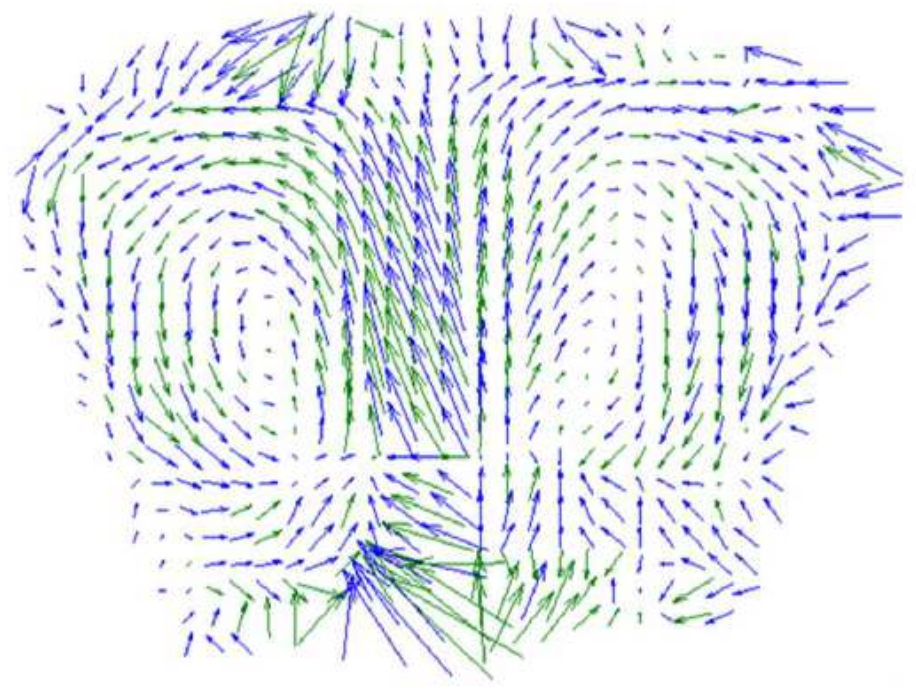

(a) PIV result

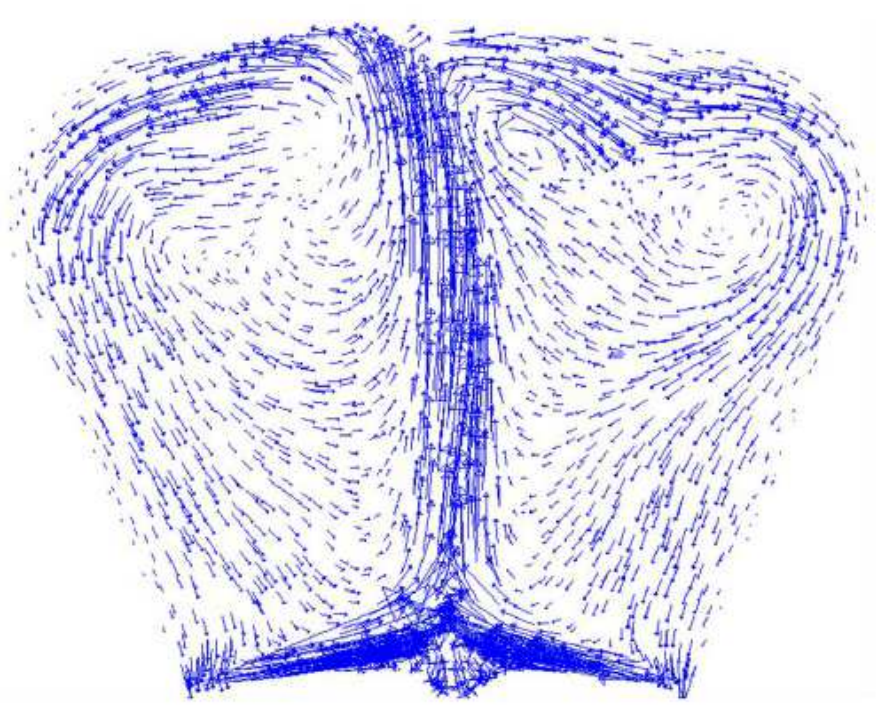

(b) Fluent result

Figure 29

Trace when inlet 1 and inlet 2 are $0.04 \mathrm{MPa}$

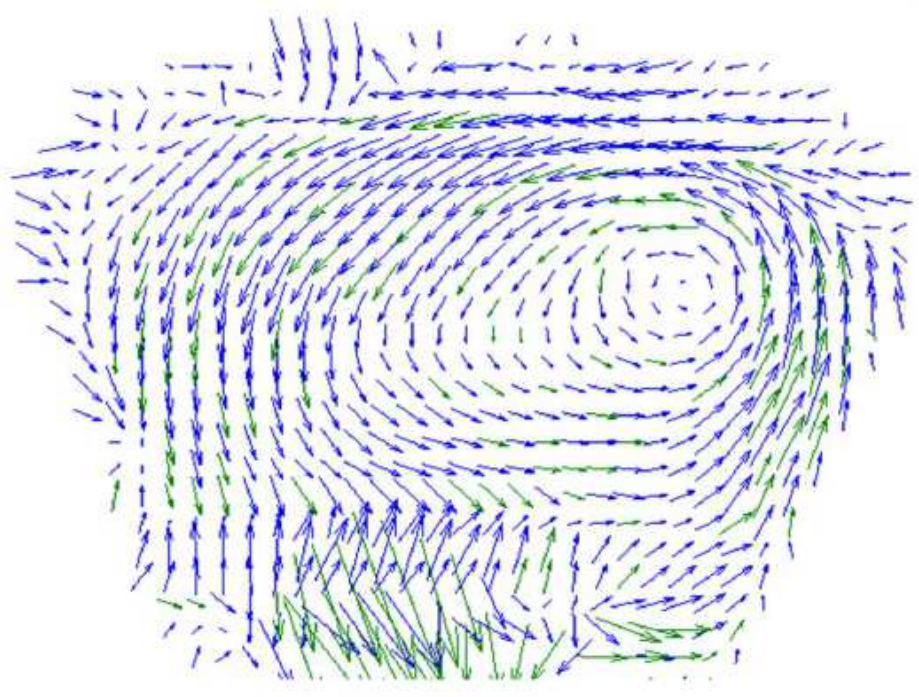

(a) PIV result

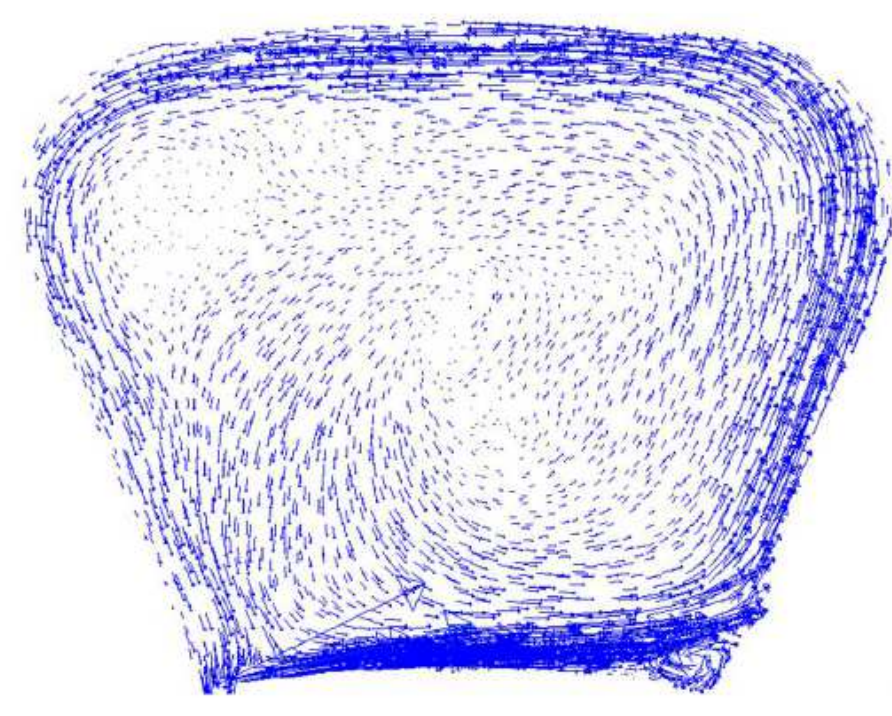

(b) Fluent result

Figure 30

Trace when inlet 1 is $0.04 \mathrm{MPa}$ and inlet 2 is $0 \mathrm{MPa}$ 


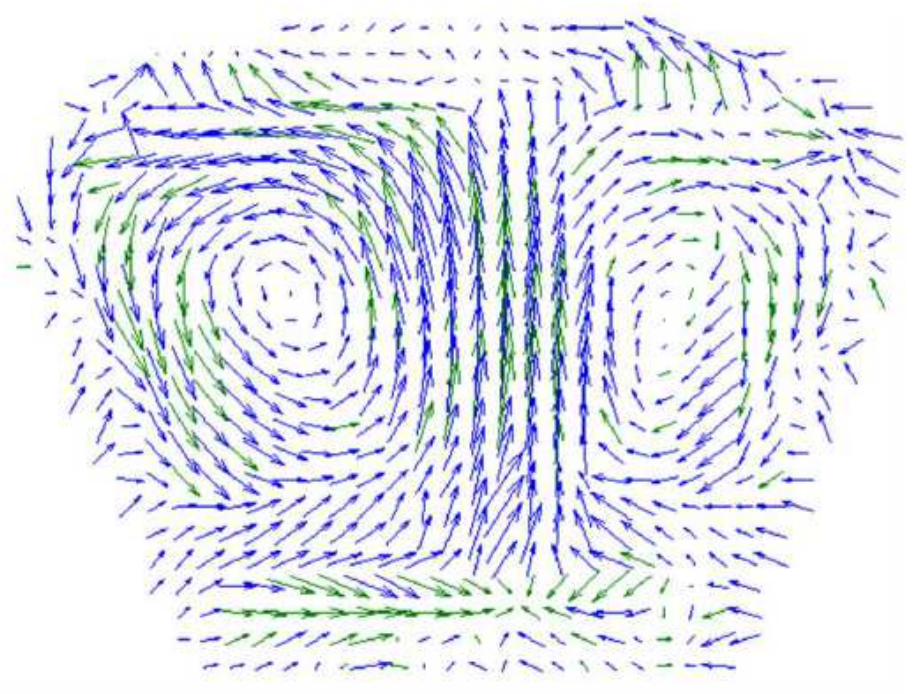

(a) PIV result

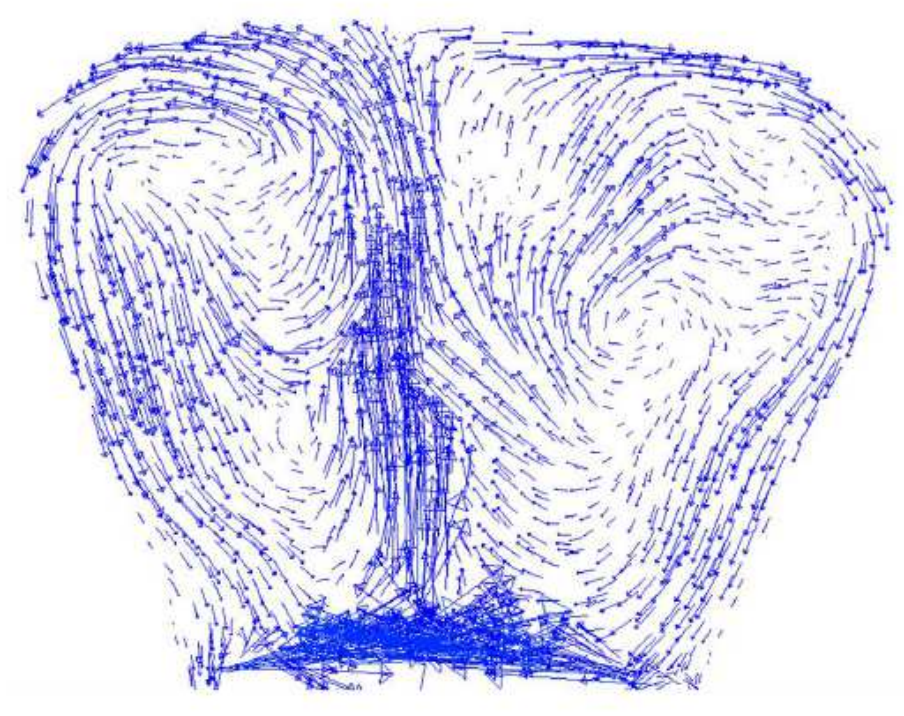

(b) Fluent result

Figure 31

Trace when inlet 1 and inlet 2 are $0.06 \mathrm{MPa}$

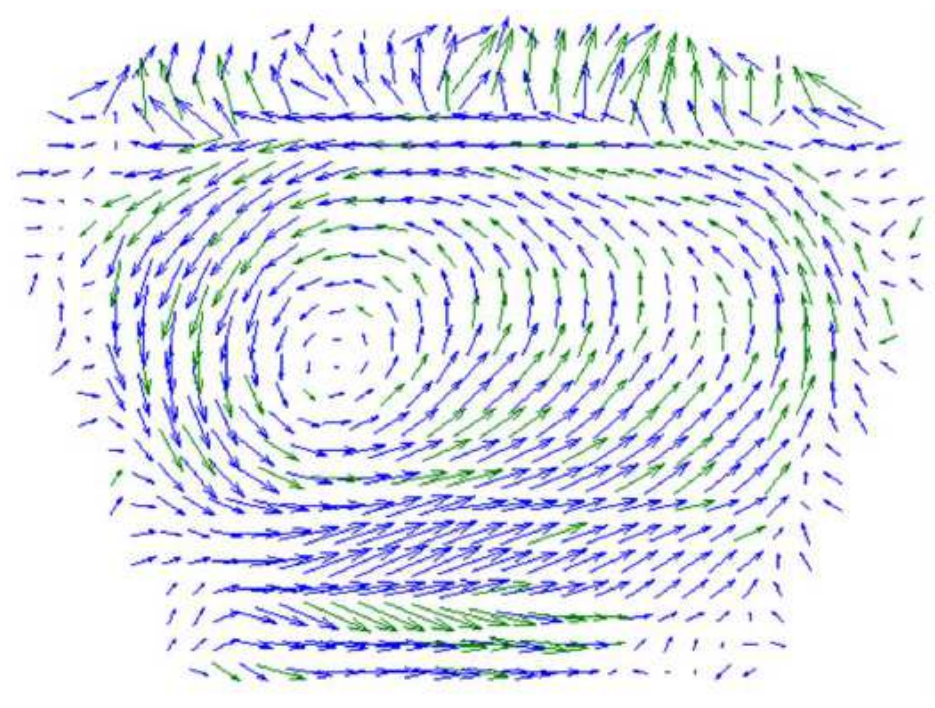

(a) PIV result

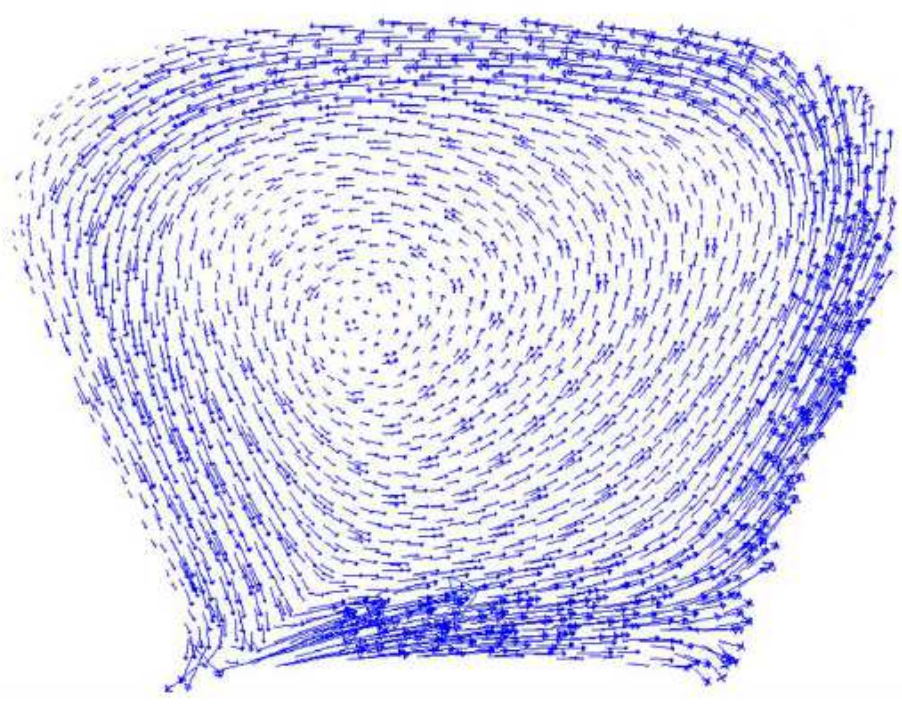

(b) Fluent result

Figure 32

Trace when inlet 1 is $0.06 \mathrm{MPa}$ and inlet 2 is $0 \mathrm{MPa}$ 


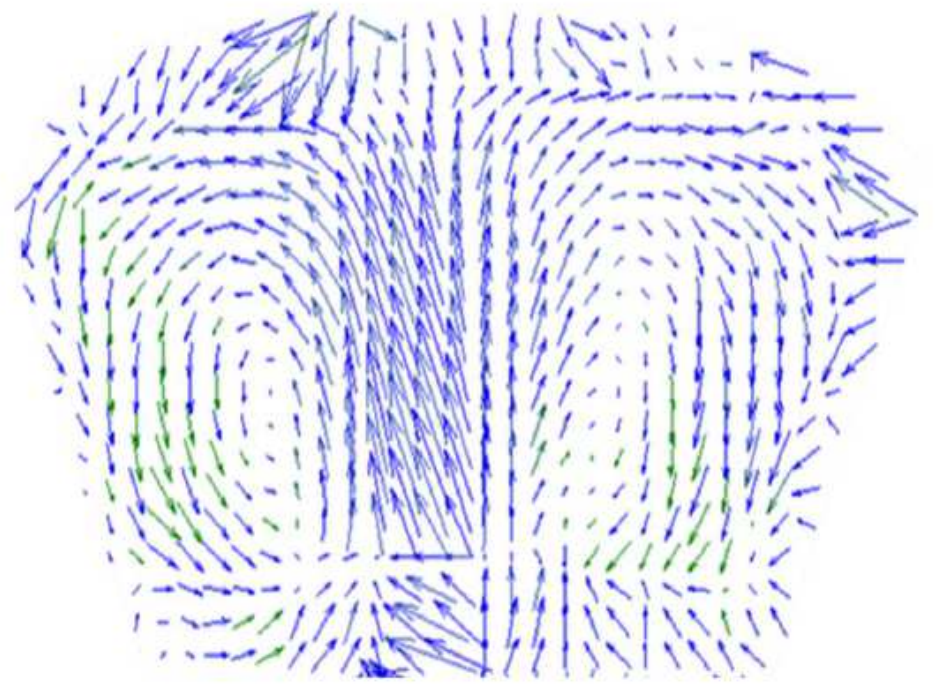

(a) PIV result

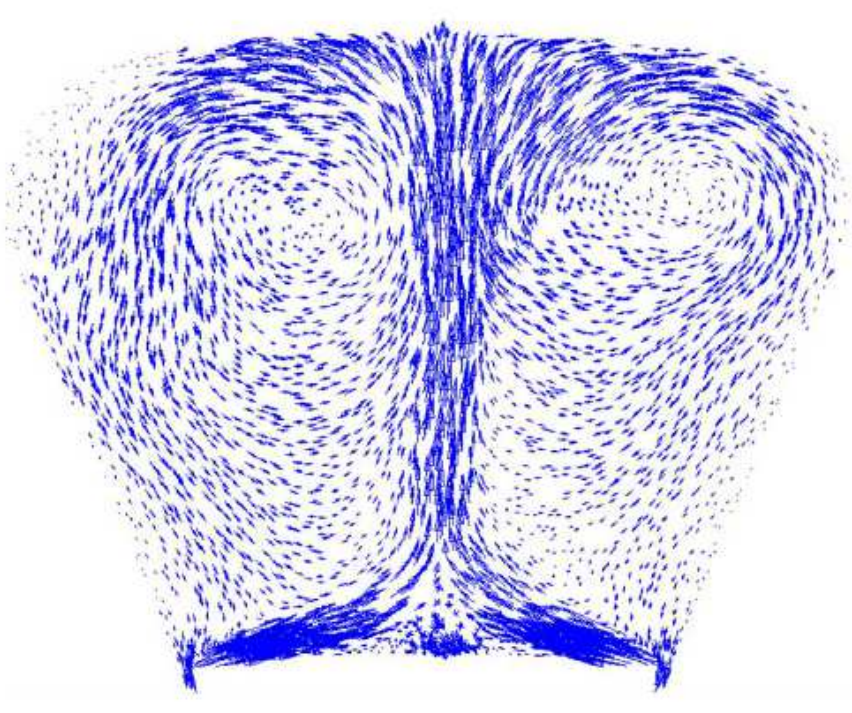

(b) Fluent result

Figure 33

Trace when inlet 1 and inlet 2 are $0.08 \mathrm{MPa}$

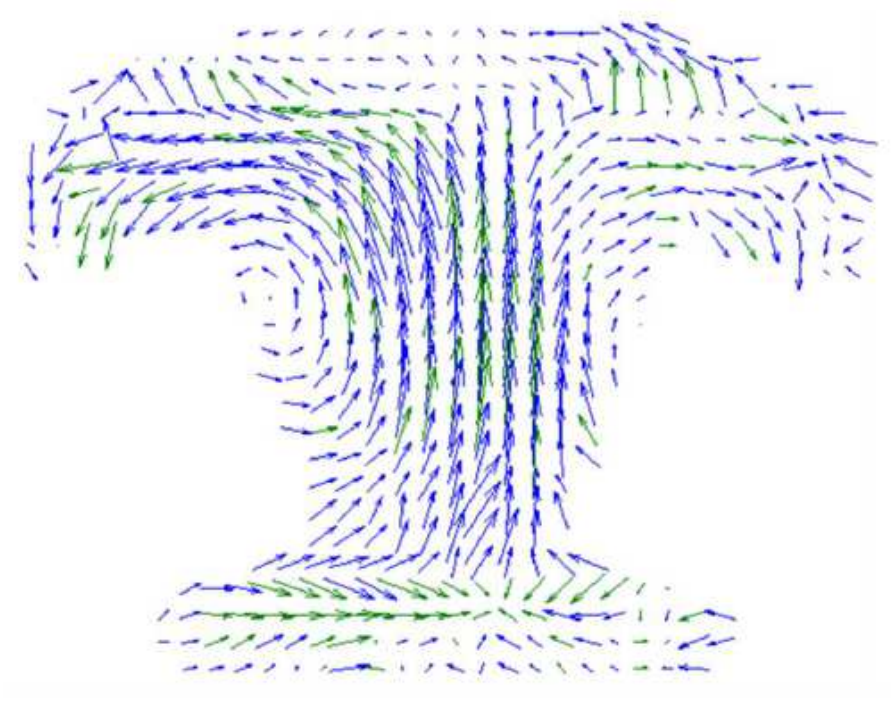

(a) PIV result

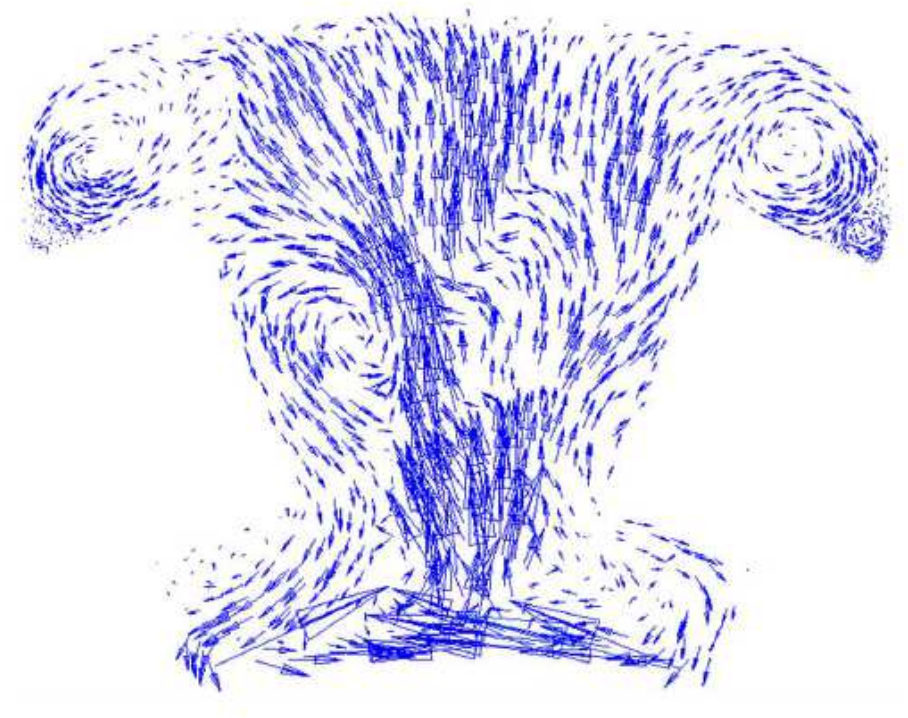

(b) Fluent result

Figure 34

Trace with coil model when inlet 1 and inlet 2 are $0.04 \mathrm{MPa}$ 